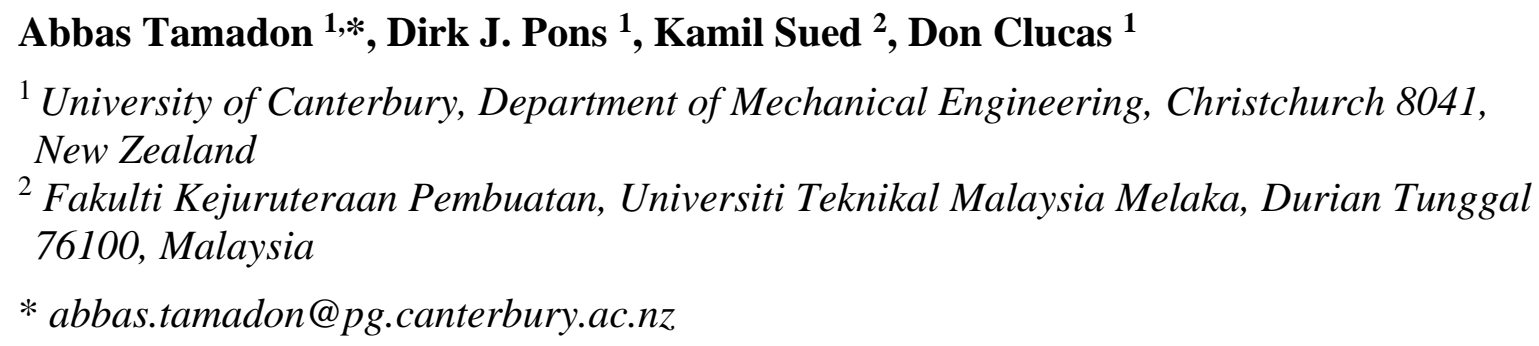

\title{
INTERNAL FLOW BEHAVIOUR AND MICROSTRUCTURAL EVOLUTION OF THE BOBBIN-FSW WELDS: THERMOMECHANICAL COMPARISON BETWEEN 1XXX AND 3XXX ALUMINIUM GRADES
}

\begin{abstract}
The influences of processing parameters and tool feature on the microstructure of AA1100 and AA3003 aluminium alloys were investigated using bobbin friction stir welding (BFSW). The research includes flow visualization and microstructural evolution of the weld texture using the metallographic measurement method. Results indicated that the operational parameters of the welding (e.g. feed rate, rotating speed) and the geometry of the tool can directly affect the flow patterns of the weld structure. The microscopic details revealed by the optical and electron microscope imply the dynamic recrystallization including grain refinement and precipitation mechanisms within the stirring zone of the weld region. The microscopic observations for the weld samples show a better performance of the fully-featured tool (tri-flat threaded pin and scrolled shoulders) compared to the simple tool without inscribed surface features. The fully-featured tool resulted in a more uniform thermomechanical plastic deformation within the weld structure along with the precipitation hardening and the homogeneity of the microstructure.
\end{abstract}

Keywords: Bobbin Friction Stir Welding; AA1100; AA3003; internal flow; thermomechanical behaviour

\section{INTRODUCTION}

Bobbin Friction Stir Welding (BFSW) is a relatively new joining technique [1-3] which has been received significant attention by industry for solid-state processing of deformable materials, e.g. aluminium alloys [4]. Compared to convention FSW (CFSW) [5], the BFSW technique is an innovative variant of the tool design [6-8]. However, to optimise the weld quality, the process parameters and operational variables need to still be fully understood.

Regarding the quality control of the weld, the CFSW also has inherent problems which need technical consideration to obtain a sound weld [9-11]. For instance, regarding the stirring zone (SZ), the improper engagement of the pin tool and the workpiece causes incomplete penetration to occur, creating discontinuity defects within the weld structure [12-14]. Moreover, the vibration disturbance needs to be avoided during the process, which requires anvil and clamping rigidity [15]. The BFSW technique as a self-reactive FSW process does not 
necessarily require the complex and relatively costly fixture and backing anvil to compensate the reactive forces to induce sufficient and effective material flow within the SZ [16]. Unlike BFSW, CFSW requires exact plunged depth for the tool so that formation of the root flaws can be avoided [17]. However, not only BFSW, but also CFSW are excellent candidates to join the aluminium alloys as the other processes of welding such as fusion welding are rarely used on such active alloys [2]. Porosity and hot cracking usually occur if the aluminium alloys discussed are fusion welded [18].

BFSW is known as a variant of FSW, however, it has very different characteristics within the weld structure, where the plastic flow regimes and the relevant microstructure is different from the physics accepted for the CFSW process [18]. The general geometry of BFSW's tool consists of two cylindrical shoulders with a pin in the middle. By rotation of this single-piece tool, the mechanical interaction between the tool components and the workpiece generates the frictional heat and plastic stirring in the contact surfaces [19]. In BFSW process the backing anvil is replaced with a rotating bottom shoulder, whereby the heat input and the plastic flow are elevated compared to the CFSW [8,20]. Moreover, the axial force required in CFSW is not required in BFSW. Instead, the compression ratio is used as the variance between the actual thickness of the workpiece and the biting gap at the edge of shoulders. This provides enough engagement between the mass and the tool during the stirring action, while the rotating tool moves along the butt-joint interface [6]. The geometry of the bobbin-tool can provide approximately symmetrical microstructure as the tool is perpendicular to the welding direction, and simultaneously rotates and advances between the advancing side (AS) and retreating side (RS) of the welding locus [7]. Eventually, the interaction between the tool and the workpiece at the working region (stirring zone, SZ) forms a symmetrical flow-pattern in the top and bottom portions of the SZ, at the proximity of the rotating tool [21]. This is observable as an hourglass pattern at the cross-section of the weld, which is different from the basin-shaped pattern of the weld-region in CFSW weld samples [22]. The special double-sided bobbin tool design can work on a material which has up to $25 \mathrm{~mm}$ thickness, because of sufficient heat which is created and maintained by the double rotating shoulders, connected by a centred-pin in the middle [23]. However, all these add complexity in flow-structure and microscopic details of the BFSW weld $[24,25]$, compared to the CFSW. Thus, there is more investigation required regarding identifying the effective variables of the BFSW process, to obtain the necessary defect-free weldment under optimized welding condition.

To achieve the higher quality in the manufacturing, the variables of the process, for instance, the design of the tool, appropriate processing parameters and the simulation of material flows need to be optimized [26]. In this paper, the potential development of BFSW is the subject of investigation, where the weld structure and internal flow details are studied for two grades of aluminium alloy. By applying different welding speeds (rotational and advancing), and different bobbin-tool designs, the effect of the tool's features and processing parameters are compared between AA1100 and AA3003 aluminium plates with the same thickness. The metallographic analysis (optical and electron microscopy) can reveal the details of the microscopic evolution and flow mechanism within the weld region.

The comparison between the microscopic characteristics of the weld region, internal flow features, and the anatomy of the defects (e.g. tunnel void) can give better understanding of the mechanism of the bobbin friction stir welding. The alteration of the weld microstructure in the middle of the stirring zone, compared to the transition regions (thermomechanically affected zone and heat affected zone) can explain the mechanical grain refinement caused by the stirring action. Also the void formation originated from the inconsistency of the welding parameters can explain the insufficient material flow within the stirring zone, induced by the rotating tool. 
Therefore, obtaining a defect-free weldment with a uniform grain structure can indicate the optimum welding parameters for the BFSW process.

\section{EXPERIMENTAL}

\section{Characteristics of AA1100 and AA3003 aluminium plates}

AA1100 is a commercially pure aluminium alloy from the $1 \mathrm{xxx}$ series of wrought aluminium-based alloys. The AA1100 alloy with a standard element composition was chosen as the best candidate for the FSW process, because of excellent deformability characteristics. The chemical purity and stabilized microstructure can easily reveal any flow-based defects or weld contamination during the FSW process. If the applied welding parameters lead to unsatisfactory results for this alloy, it likely will not be suitable for obtaining a sound weld for other grades [27].

AA3003 from 3xxx series is considered a wrought aluminium alloy with good machinability, formability, weldability, resistance of atmospheric corrosion, and moderate strength. AA3003 is wildly used in a range of industries such as chemical and food, as well as many building products. Even though AA3003 belongs to the wrought aluminium-manganese family, it is a non-heat-treatable alloy, and the microstructure cannot be adversely affected by the plastic deformation or heat-input during the FSW process. Compared to the 1xxx series, AA3003 has higher tensile and elongation strength at elevated temperature. All these make it a good candidate to be investigated for the microstructural and flow-induced properties under the FSW processing.

The chemical composition of the AA1100 and AA3003 aluminium alloys, analysed in elemental details, are listed in Table 1.

Table 1. Chemical composition of the AA1100 and AA3003 aluminium alloys, measured in elemental detail (wt. \%)

\begin{tabular}{cccc}
\hline \multicolumn{2}{c}{ AA1100 Aluminium Alloy } & \multicolumn{2}{c}{ AA3003 Aluminium Alloy } \\
\hline Chemical Element & Composition (wt.\%) & Chemical Element & Composition (wt.\%) \\
\hline Zinc $(\mathrm{Zn})$ & 0.006 & Zinc $(\mathrm{Zn})$ & 0.10 \\
Manganese $(\mathrm{Mn})$ & 0.016 & Manganese $(\mathrm{Mn})$ & 1.20 \\
Silicon $(\mathrm{Si})$ & 0.138 & Silicon $(\mathrm{Si})$ & 0.60 \\
Copper $(\mathrm{Cu})$ & 0.090 & Copper $(\mathrm{Cu})$ & 0.12 \\
Iron $(\mathrm{Fe})$ & 0.182 & Iron $(\mathrm{Fe})$ & 0.70 \\
Chromium $(\mathrm{Cr})$ & 0.030 & Zirconium $(\mathrm{Zr})$ & 0.10 \\
Magnesium $(\mathrm{Mg})$ & 0.007 & Cobalt $(\mathrm{Co})$ & 0.10 \\
Aluminium $(\mathrm{Al})$ & Balance & Aluminium $(\mathrm{Al})$ & Balance \\
\hline
\end{tabular}

\section{The features of the Bobbin-tool}

The significant components of the bobbin-tool are a pin, connected between the top and bottom shoulders. For a uniform flow regime induced by the tool action, the pin is required to have a symmetrical design. To increase the efficiency of stirring action, a thread like feature is usually required as it can benefit the vertical material flow circulation at the proximity of the 
pin. However, it cannot be excessively coarse on the pin, because of the consequence of excessive flash, or clogging by the plastic mass. The existence of grooves could create vertical resistance and cause remnants of material on the pin, which is also known as cutting effect [28]. As a result, while the tool is keeping adequate heat to break the boundary of grains when it transverses to certain welding directions, the material in the SZ does not fully bond with adjacent portions. Also, threads in the pin should be designed either only on clockwise or anticlockwise, otherwise the material flow could be stalled or delivered from the centre to the surface and increase defects such as incomplete joints, voids and beads, as inappropriate flows are produced by unsuitable direction of the threads. The flat feature helps the bonding process, which has a similar function during the stirring as the thread but in the horizontal direction [29]. Another well-known feature is the scroll patterns which inscribe a spiral pattern on each of the shoulders [30-33]. The process of recrystallization and reforming grains is affected significantly by the shoulder, as the heat which is created from the friction of the shoulder and also the pin. The spiral scrolls on the shoulder, similar to the pin threads can conduct the mass flow inwards, and avoid the escaping of the plastic mass from between the shoulder and workpiece, while the rotating tool moves forward through the weld-line. Consequently, the compression ratio for the spacing of the gap between shoulders is particularly important to produce the compression of the mass flow mixing from the AS and RS at the proximity of the pin, while the rotating tool travels forward.

Two variants of BFSW tools are used in this experimental work, while the tool dimensions are the same, the surface geometrical features are different (Figure 1). A single-piece bobbintool without any surface features were utilized for BFSW welding of AA1100 plates, as it is considered the basic soft material will show the principles of this solid-state processing (Figure 1a). A fully-featured fixed-gap bobbin-tool comprises a tri-flat threaded pin, and scrolled shoulders were considered for the processing of the AA3003 plates (Figure 1b). Both bobbintools were made of $\mathrm{H} 13$ tool steel, with hardness of $560 \mathrm{HV}$. The geometric details of the bobbin-tools are listed in Table 2.
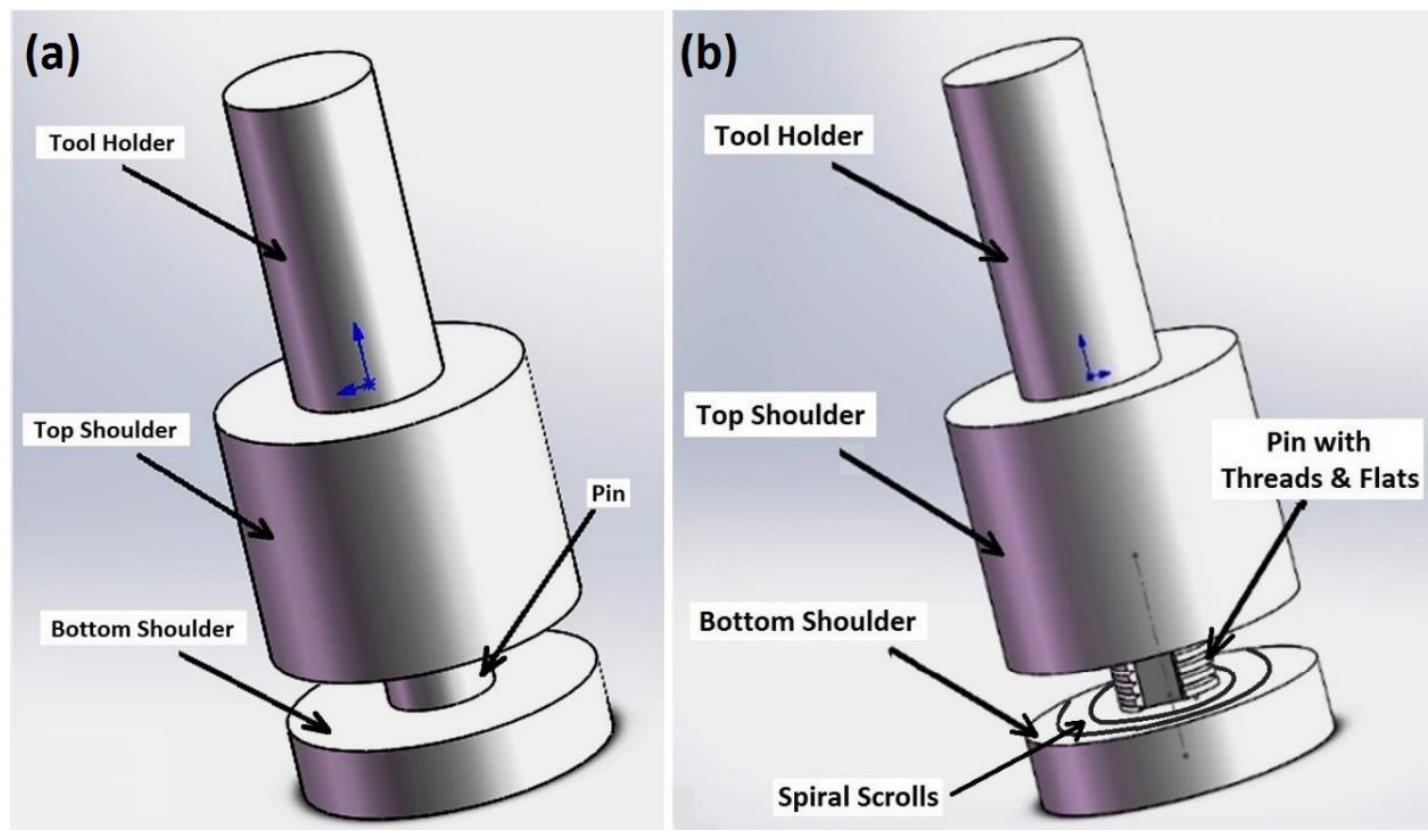

Fig. 1. 3D schematic of the bobbin-tools, utilised for the welding of the aluminium plates; (a) singlepiece bobbin-tool without surface features, utilised for BFSW processing of the AA1100 aluminium plates, (b) fully featured (threaded tri-flat pin, with scrolled shouldered) fixed-gap bobbin-tool (threads that run in one direction), used to weld the AA3003 aluminium plates 
Table 2. Geometric details of the bobbin-tools utilised for BFSW processing of AA1100 and AA3003 aluminium plates

\begin{tabular}{ccc}
\hline Bobbin-tool & $\begin{array}{c}\text { Simple tool } \\
\text { (used for AA1100) }\end{array}$ & $\begin{array}{c}\text { Fully-featured tool } \\
\text { (used for AA3003) }\end{array}$ \\
\hline Tool holder & $12 \mathrm{~mm}$ (diameter), & $12 \mathrm{~mm}$ (diameter), \\
26 mm (height) & $26 \mathrm{~mm}$ (height) \\
Top shoulder & $18 \mathrm{~mm}$ (diameter), & $18 \mathrm{~mm}$ (diameter), \\
& $20 \mathrm{~mm}$ (height) & $20 \mathrm{~mm}$ (height) \\
Pin & $8.5 \mathrm{~mm}$ (diameter), & $8.5 \mathrm{~mm}$ (diameter), \\
& $5.8 \mathrm{~mm}$ (height) & $5.8 \mathrm{~mm}$ (height) \\
Bottom shoulder & $18 \mathrm{~mm}$ (diameter), & $18 \mathrm{~mm}$ (diameter), \\
& $7 \mathrm{~mm}$ (height) & $7 \mathrm{~mm}$ (height) \\
Number of threads & None & 3 \\
Number of flats & None & 3 \\
Compression ratio & $3.75 \%$ & $3.75 \%$ \\
\hline
\end{tabular}

\section{Welding processing}

The AA1100 and AA3003 aluminium plates of $6 \mathrm{~mm}$ thickness were used as the workpiece material for two sets of $1 \mathrm{xxx}$ and $3 \mathrm{xxx}$ welding trials, respectively. For each welding test, two plates were arranged side-by-side, with the dimensions of $250 \mathrm{~mm}$ (length) $\times 75 \mathrm{~mm}$ (width) $\times$ $6 \mathrm{~mm}$ (thickness), in the butt-joint position with no gap between the plates. To compare the weld structure in different conditions of the welding process, a variety of the welding speeds, clockwise rotational speed, $\omega$, and advancing longitudinal speed, V, were applied for the study of the weld texture and flow behaviour in different stirring regimes. In this regard, a set of tests were run at $\omega(350-600 \mathrm{rpm})$ and V (150-400 $\mathrm{mm} / \mathrm{min})$. Six sets of speed values $(\omega, \mathrm{V})$ were selected for AA1100 and AA3003 plates, applied in identical welding condition, only with different bobbin-tool designs for each grade. Table 3 presents the condition of welding trials in detail. A 3-axis CNC machine (model MX-45VAE, OKUMA brand, Japan) was utilized for welding of the plates, rigidly fixed under the fixture and strap clamps, with no pre-heating or post-heating treatment during the process. After conducting a single-pass weld-line, the weldments were cut along the transverse direction, at the middle of the weld locus for the metallographic measurements.

Table 3. Specification of the operation parameters for the AA1100 and AA3003 BFSW weld sample

\begin{tabular}{|c|c|c|c|c|c|c|c|c|}
\hline \multicolumn{3}{|c|}{ Welding Speed Sets } & \multirow{2}{*}{\multicolumn{2}{|c|}{ Aluminium Grade }} & \multirow[t]{2}{*}{ Tool feature } & \multirow{2}{*}{$\begin{array}{c}\text { Tool } \\
\text { Material }\end{array}$} & \multirow{2}{*}{$\begin{array}{l}\text { Tool } \\
\text { Entry }\end{array}$} & \multirow{2}{*}{$\begin{array}{c}\text { Working } \\
\text { Temperature }\end{array}$} \\
\hline $\begin{array}{c}\omega \\
\mathrm{rpm}\end{array}$ & $\begin{array}{c}\mathrm{V} \\
\mathrm{mm} / \mathrm{min}\end{array}$ & $\begin{array}{l}\text { Advance per } \\
\text { Revolution } \\
\text { (APR) mm }\end{array}$ & & & & & & \\
\hline 350 & 150 & 0.428 & \multirow[t]{6}{*}{ AA 1100} & \multirow[t]{6}{*}{ AA3003 } & \multirow{3}{*}{$\begin{array}{c}\text { Simple bobbin- } \\
\text { tool } \\
\text { (AA1100) }\end{array}$} & \multirow{3}{*}{$\begin{array}{l}\text { H13 } \\
\text { Tool } \\
\text { Steel }\end{array}$} & \multirow[t]{3}{*}{ Plate Edge } & \multirow[t]{3}{*}{$18^{\circ} \mathrm{C}$} \\
\hline 400 & 200 & 0.500 & & & & & & \\
\hline 450 & 250 & 0.555 & & & & & & \\
\hline 500 & 300 & 0.600 & & & \multirow{3}{*}{$\begin{array}{c}\text { Full-featured } \\
\text { bobbin-tool } \\
\text { (AA3003) }\end{array}$} & \multirow{3}{*}{$\begin{array}{l}\text { H13 } \\
\text { Tool } \\
\text { Steel }\end{array}$} & \multirow[t]{3}{*}{ Plate Edge } & \multirow[t]{3}{*}{$18^{\circ} \mathrm{C}$} \\
\hline 550 & 350 & 0.636 & & & & & & \\
\hline 600 & 400 & 0.666 & & & & & & \\
\hline
\end{tabular}




\section{Metallography procedure}

To achieve the required standard of smooth mirror surface for etching and metallographic measurements, all the samples were manually ground and micro-polished. Then, using different etching solutions the microscopic details and flow structures were revealed. By using the light optical microscope (Olympus Metallurgical Microscope, Tokyo, Japan), and Scanning Electron Microscope (SEM) machine (JEOL 6100, JEOL Inc., Peabody, MA, USA) equipped with the Electron Backscatter Diffraction (EBSD) detector (HKL Nordlys III, Oxford Instruments plc, UK), the details of the microstructure were analysed via micrograph images. The details of the metallographic measurement are introduced in the next section. Figure 2 shows the analysing procedure.

The cross-section samples were mounted using EpoFix resin to be safe from any physical distortion and increase the efficiency of the polishing procedure. The mixed resin powder and hardener were cast in a cylindrical mould container, while the sample was placed faced down in the container, fully covered by the resin material. The Buehler Grinder was used for the entire process of grinding and miro-polishing of the mounted samples. Initially, the trial of grinding was conducted via the fixture (Figure 3 ) followed by the manual polishing, according to the instruction listed in Table 4. The smooth mirror surface was attained through the micropolishing procedure with a series of Polycrystalline Diamond Suspensions (PDS) from $9 \mu \mathrm{m}$ to $0.6 \mu \mathrm{m}$ (1 sec. spray and 30sec. off). For the final step of micro-polishing, the samples were polished with a micro-cloth pad with Master Met (Colloidal Silica Polishing Suspension) and a stream of deionised water instead of PDS. The final polished samples were washed by ethyl alcohol, and then dried using hot air.

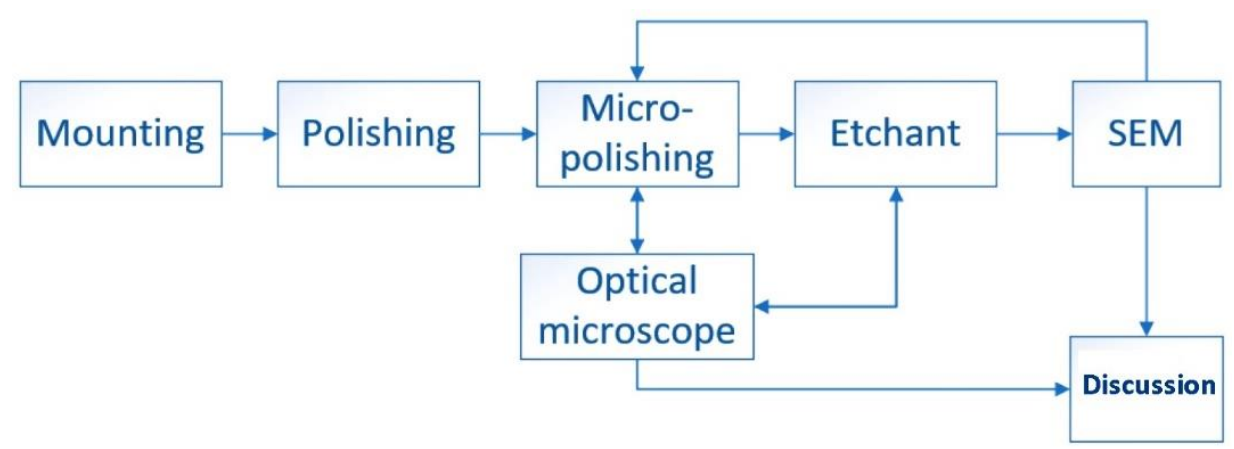

Fig. 2. The flow of the metallography procedure indicated how the trial is done
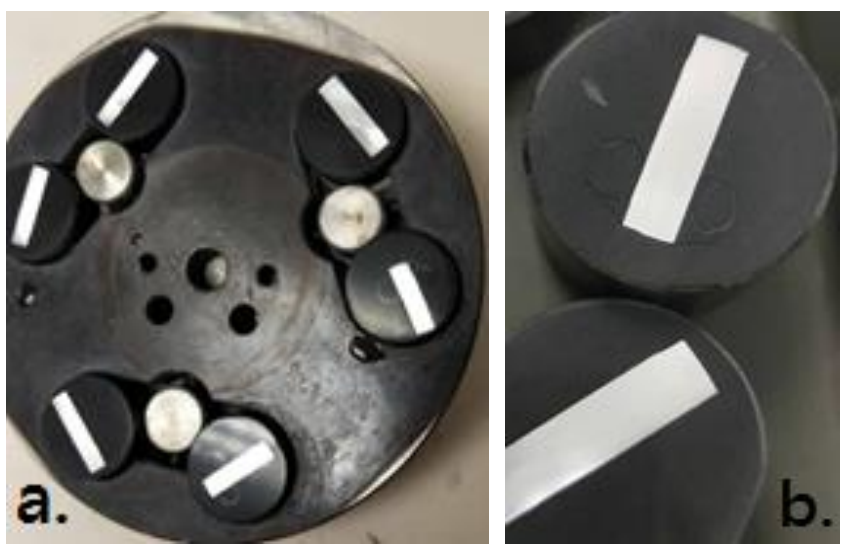

Fig. 3. Grinding of mounted samples; (a) Fixture of the automatic grinder; (b) Mounted samples 
The AA1100 weld samples were etched by a direct immersion the Keller's etchant $(95 \mathrm{~mL}$ $\mathrm{H}_{2} \mathrm{O}, 2.5 \mathrm{~mL} \mathrm{HNO}_{3}, 1.5 \mathrm{~mL} \mathrm{HCl}, 1.0 \mathrm{~mL} \mathrm{HF}$ ), for 30 seconds at $50^{\circ} \mathrm{C}$. The AA3003 weld samples were etched using a reagent solution of $\left(25 \mathrm{~mL} \mathrm{CH} 3 \mathrm{OH}_{2} 25 \mathrm{~mL} \mathrm{HCl}, 25 \mathrm{~mL} \mathrm{HNO}_{3}\right.$, and 1 drop HF), for 60 seconds at $70^{\circ} \mathrm{C}$.

Table 4. Details of grinding and polishing procedures for the samples preparation required for metallographic measurements

\begin{tabular}{|c|c|c|c|c|c|}
\hline \multirow[t]{5}{*}{ Grinding stage } & Surface & Rotating speed & Direction & Force on sample & Time \\
\hline & P180-grit & \multirow[t]{4}{*}{$120 \mathrm{rpm}$} & \multirow[t]{4}{*}{$+90^{\circ}$} & \multirow[t]{2}{*}{ Around 6 Lbs. } & \multirow{2}{*}{$\begin{array}{l}2 \mathrm{~min} / \mathrm{pad} \text { or till } \\
\text { plane }\end{array}$} \\
\hline & P280-grit & & & & \\
\hline & P400-grit & & & \multirow[t]{2}{*}{ Around 5 Lbs. } & \multirow{2}{*}{$\begin{array}{l}3 \mathrm{~min} / \mathrm{pad} \text { or till } \\
\text { plane }\end{array}$} \\
\hline & P600-grit & & & & \\
\hline \multirow[t]{6}{*}{ Polishing stage } & $\begin{array}{l}\text { Polishing } \\
\text { suspension }\end{array}$ & Rotating speed & Direction & Force on sample & Time \\
\hline & $9 \mu \mathrm{m}$ PDS & \multirow[t]{6}{*}{$120 \mathrm{rpm}$} & \multirow[t]{6}{*}{$+90^{\circ}$} & \multirow[t]{4}{*}{ Around 5 Lbs. } & \multirow{4}{*}{$\begin{array}{l}3 \mathrm{~min} / \mathrm{PDS} \text { or till } \\
\text { smooth surface }\end{array}$} \\
\hline & $6 \mu \mathrm{m}$ PDS & & & & \\
\hline & $3 \mu \mathrm{m}$ PDS & & & & \\
\hline & $1 \mu \mathrm{m}$ PDS & & & & \\
\hline & $0.6 \mu \mathrm{m}$ PDS & & & \multirow[t]{2}{*}{ Around 8Lbs } & $\begin{array}{l}3 \mathrm{~min} / \mathrm{PDS} \text { or till } \\
\text { mirror surface }\end{array}$ \\
\hline $\begin{array}{l}\text { Final micro- } \\
\text { polishing stage }\end{array}$ & (MasterMet) & & & & $3 \mathrm{~min}$ \\
\hline
\end{tabular}

\section{RESULTS AND DISCUSSION}

\section{Material flow mechanism}

Figures 4 and 5 show the macro-etched cross-sections of the AA1100 and AA3003 weld samples, respectively. In each set of cross-sections, different welding speeds were tested to compare the differences of internal flow features within the weld structure, altered by the various stirring conditions.

As shown in Figure 4 for the AA1100 BFSW welds, the plastic flow patterns are observed at the centre of the SZ towards the AS border. These flow patterns reveal the flow lines of the deposited mass at the traverse section of the trailing edge of the tool, once it leaves the location of the stirring action.

Three different flow patterns can be generally categorized from the macro-etch observations of the AA1100; S-line-shape flow (Figures 4a,b), ellipse-flow (Figures 4c,d), swirling-flow (Figures 4e,f). As shown by hatch-lines in the middle of the SZ (Figures 4a,b), the S-line in lower speeds represents the stirring action with a concentration at the proximity of the tool. The flow pattern has more depth in the mid-SZ, rather than the sub-shoulder area. Therefore, the S-line flow is mostly induced by the pin action at the centre of the weld breadth. By the increase in welding speeds ratio, the plastic flow pattern changes to an ellipse-shaped flow, which extends from the centre of the weld towards the underneath of the shoulders (Figures $4 \mathrm{c}, \mathrm{d}$ ). The ellipse flow shows a more uniform thermomechanical deformation feature, compared to the primary S-line flow pattern. The third flow pattern at the butting surface of the 
AA1100 weld is the swirling flow lines. This splitting shaped of the flow lines is mostly similar to the onion ring patterns of the CFSW weld $[34,35]$. The macrostructure of the BFSW welds (Figures 4e,f) shows the segregation bands morphology at the middle of the SZ, elongated towards the top and bottom shoulders. It is attributed to the increase of the welding speeds, where the shoulder -because of more contact surface, compared to the pin-has a dominant role in the stirring action. Therefore, the ellipse-shaped flow patterns of the swirling plastic region are revealed in the sub-shoulder regions. The flow partitioning within the swirling structure reduces the integrity of the flow regimes. This leads to the emergence of discontinuity defects, e.g. tunnel void, within the stirring zone, as it observed in Figure 6e.

Figure 5 shows the weld cross-sections of the AA3003 aluminium alloy in different sets of speeds, similar to the AA1100 samples, processed by a fully-featured bobbin-tool. The lack of plastic flow at the stirring zone of the weld points to the homogeneity of the mass flow induced by the proper tool performance. The fully-featured tool can create more severe frictional heat because of the increased contact surface between the tool components and the workpiece materials. Therefore for the AA3003 samples, the heat input generated at specific welding speeds is higher than the stirring action observed of the AA1100 samples with the plain tool. This can form more uniform plastic deformation, with more sufficient intermixing between the plastic layers flowing within the stirring zone. Therefore, the flow band structures are mostly unified without any segregation effect which can be delineated with the etchant reagent. However, still, the hourglass borders of the stirring zone are distinct from the base metal region, distinguishing the intense plastic deformation through the etched cross-sections.

However, at the elevated speeds (Figures 5e,f), the segregated flow-arms are observed widespread around the emerged tunnel void towards the AS border. This can be because of the higher strength of the material (AA3003, compared to AA1100), affecting the viscoplasticity of the plastic mass at higher speeds. Moreover, the elevated welding speeds can cause a relative flow inconsistency at the leading and trailing edge of the rotating tool. The simultaneous rotation and advancement of the tool along the joint-line causes a plasticized mass flow circulating around the rotating pin which needs enough time to spatially be deposited at the trailing edge of the tool. The elevated feeding rate probably interrupts the refilling process of the mass on the AS position of the weld, therefore the flow discontinuity occurs at the tunnel void defect region, which is revealed in Figures 5e,f.

The tunnel void opens by the increase of the welding speed, surrounded by the flow patterns elongated upwards and downwards on the AS border. At the elevated speeds (rotational and advancing), the plastic mass flow is mostly transferred by the shoulder action, rather than pumping by the rotating pin in the middle of the SZ. Therefore, because the pin action is not enough to overcome the inducing flows by the symmetrical shoulders, the refilling mechanism cannot form uniform flow integrity during the mass deposition at the trailing edge of the tool. This causes a gap between the flow layers near the pin abutting, where is the location of the tunnel void discontinuity, while the surrounding flow-arms are gradually elongated to both top and bottom sub-shoulder surface regions.

For both AA1100 and AA3003, the material flow patterns in maximum speeds $(600 \mathrm{rpm}$, $400 \mathrm{~mm} / \mathrm{min}$ ) have a suitable uniformity and visibility within the SZ matrix. The visualization of the micro-flow patterns in higher magnification can reveal more details of the flow mechanism during the stirring action of the weld. Figure 6 shows two typical flow pattern selected from the stirring zone of the AA1100 and AA3003 welds, both processed at $600 \mathrm{rpm}$ and $400 \mathrm{~mm} / \mathrm{min}$, but with different bobbin tools. Figure 6a demonstrated the swirling flow pattern for the AA1100 sample. Figure $6 \mathrm{~b}$ shows the ellipse-shaped flow pattern for the flowarms within the SZ of the AA3003 weld sample. Both layered flow patterns show an onion ring shape, similar to the CFSW weld. However, the shear bands are mostly bending as extending 
upwards and downwards towards the sub-shoulder regions. Higher magnification of the flowarms for respective samples (Figure 6c,d) reveal similar morphology for the micro-flow packets forming the deposited mass layers. This implies the similarity of the stirring flow mechanism in both samples with different material and tool features. In fact, it shows the micro-flow mechanism mostly is depended on the welding speeds rather than the workpiece material or geometrical features of the tool components. However, on the macro-scale level, the flow patterns have different shapes.

While the vertical flow features appear to be spaced at the approximately correct distance per revolution (See Figures $4 \mathrm{c}$ and $4 \mathrm{~d}$ ), the further flow patterns indicate the crack formation within the stirring structure (See Figures $5 \mathrm{e}$ and $5 \mathrm{f}$ ).

This can be explained as below: In the first steps of the mass flow deposition, the defectfree weld flow lines uniformly are dispersed from the mid-SZ towards the hourglass border at AS. However, the presence of a forging force induced by the rotating shoulders [36] can affect the refilling of the flow lines to form a bent-shaped hourglass boundary. The intensified shoulder-driven forging force can eventually cause a failure in refilling deposition of the flow regimes. Consequently, un-bonded layers of the refilled mass cause a discontinuity in the form of an open tunnel void.

The microstructural measurements for the most extreme processing condition $(600 \mathrm{rpm}$, $400 \mathrm{~mm} / \mathrm{min}$ ) shows the formation of the tunnel void defect and the severe DRX mechanism in resulting in precipitation. Although there is no solid theory regarding these mechanisms, we provide some interpretation based on the microscopy observations.

The macro-scale flow patterns within the cross-sections (Figures $5 \mathrm{e}$ and $5 \mathrm{f}$ ) confirm the occurrence of the actual void at the elevated speeds $(600 \mathrm{rpm}, 400 \mathrm{~mm} / \mathrm{min})$ of the rotating tool. It suggests an inconsistency between the stirring and the refilling processes during the mass flow transportation at the proximity of the pin tool in sub-shoulder regions. Therefore, the difficulties in controlling the refilling of the stirred layers lead to the deteriorating of the integrity of the deposited mass. This creates a discontinuity-shaped of the voids.

Figure 7 shows the schematic of different plastic flow mechanisms observed in the stirring zone of the AA1100 and AA3003 BFSW weld samples. These schematic flow patterns are drawn based on the macroscopic observations of the weld cross-sections in Figures 4-6. The dark hatched-lines are representative of the shearing bands forming the flow-arms existing within the plasticised mass between the mid-SZ and the AS border. The arrows elucidate the refilling process at the trailing edge of the tool during the deposition of the stirred mass. Different processing condition comprises the geometrical features of the bobbin tool, welding speed or workpiece material, can influence the nature of the plastic flow mechanism in macroscale and construct different flow pattern morphologies within the cross-section of the SZ. The backward flow profile is the inherent pattern observable from the metallography of the weld; therefore, regardless the flow situation at the leading edge of the tool, our interpretation only considers the flow transportation related to the mass deposition behind the tool, from the RS towards the AS. The details of the formation mechanism of the flow-induced defects are also absent in our flow interpretation, as there was not enough elucidating evidence for it in our microstructural observation. 


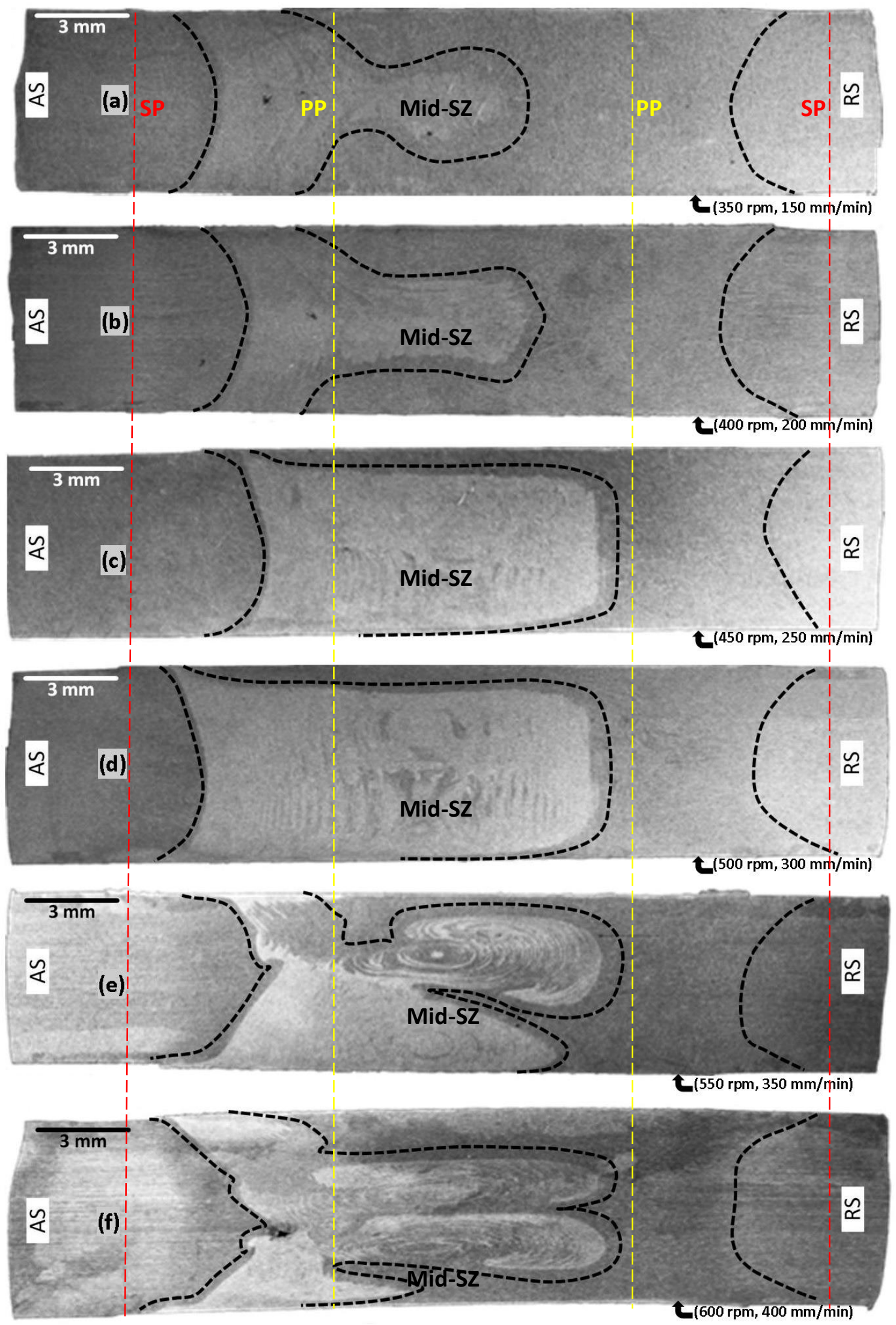

Fig. 4. Macro-etched cross-section of the AA1100 BFSW welds in different welding speeds; (a) $350 \mathrm{rpm}, 150 \mathrm{~mm} / \mathrm{min}$, (b) $400 \mathrm{rpm}, 200 \mathrm{~mm} / \mathrm{min}$, (c) $450 \mathrm{rpm}, 250 \mathrm{~mm} / \mathrm{min}$, (d) $500 \mathrm{rpm}, 300 \mathrm{~mm} / \mathrm{min}$, (e) $550 \mathrm{rpm}, 350 \mathrm{~mm} / \mathrm{min}$, (f) $600 \mathrm{rpm}, 400 \mathrm{~mm} / \mathrm{min}$. (SP: shoulder position, PP: pin position) 


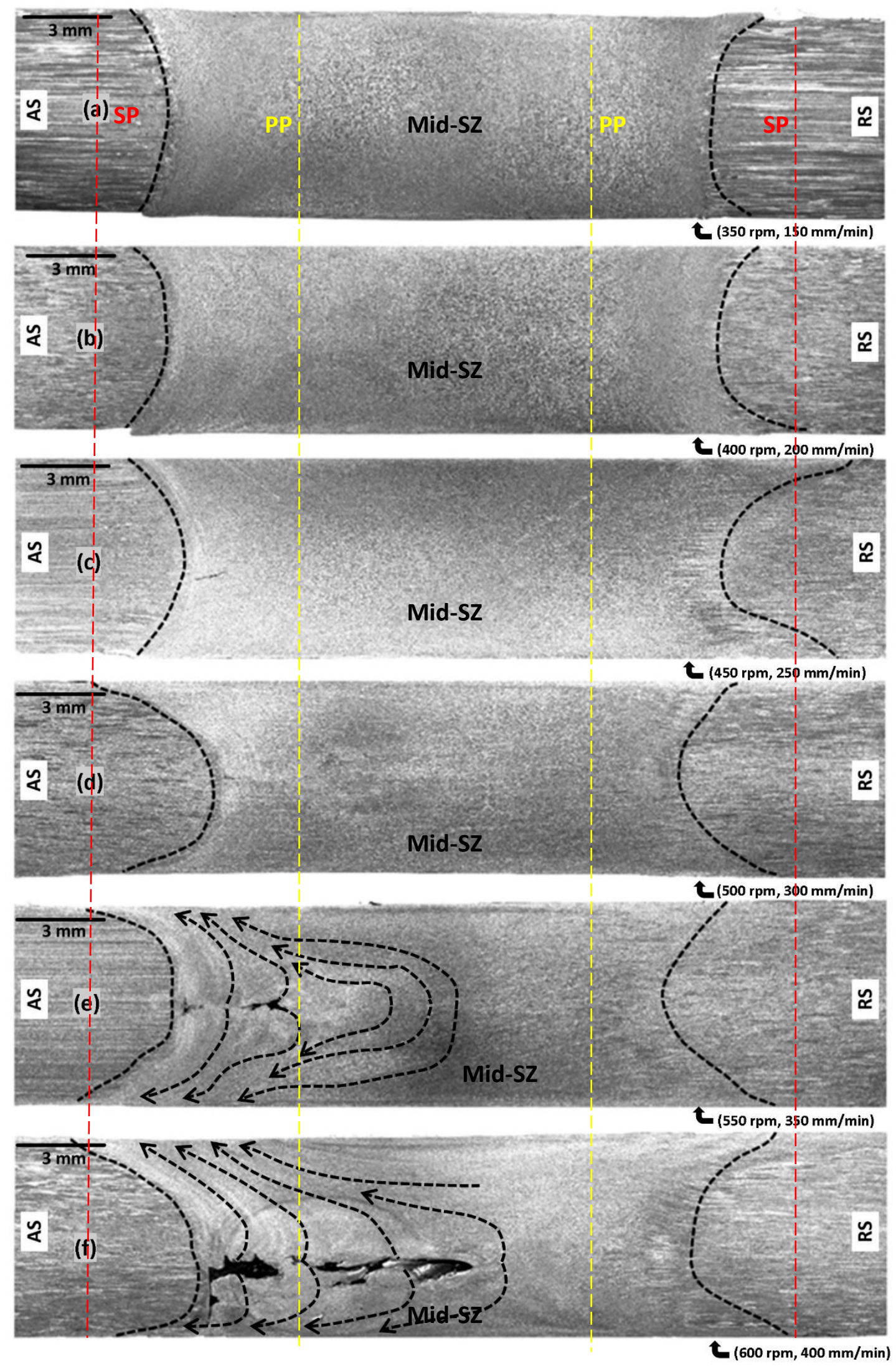

Fig. 5. Macro-etched cross-section of the AA3003 BFSW welds in different welding speeds; (a) $350 \mathrm{rpm}, 150 \mathrm{~mm} / \mathrm{min}$, (b) $400 \mathrm{rpm}, 200 \mathrm{~mm} / \mathrm{min}$, (c) $450 \mathrm{rpm}, 250 \mathrm{~mm} / \mathrm{min}$, (d) $500 \mathrm{rpm}, 300 \mathrm{~mm} / \mathrm{min}$, (e) $550 \mathrm{rpm}, 350 \mathrm{~mm} / \mathrm{min}$, (f) $600 \mathrm{rpm}, 400 \mathrm{~mm} / \mathrm{min}$. (SP: shoulder position, PP: pin position) 


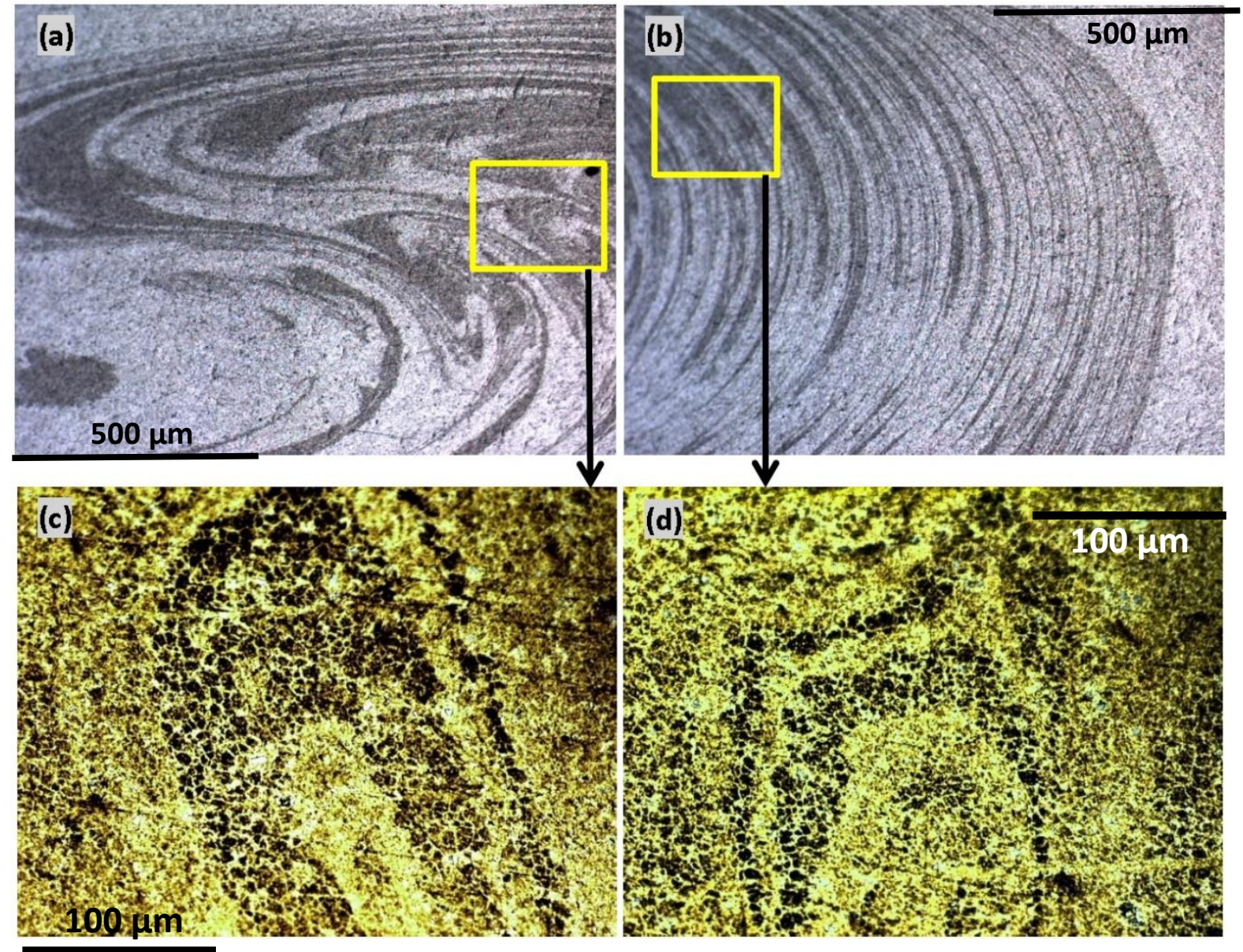

Fig. 6. Optical microscopy of micro-flow arms for the AA1100 (a, c) and AA3003 (b, d) weld samples, both processed at the welding set of $(600 \mathrm{rpm}, 400 \mathrm{~mm} / \mathrm{min})$

The flow bonding is the general result of the simultaneous effect of the tool components (symmetrical shoulders and the centered pin), generating the plasticization and shearing through the stirring mass. The heat input as the direct outcome of the mechanical stirring softens the mass and the subsequent rotation and movement induced by the tool activate the shearing flow through the yielded mass. The intercalation of the plasticised layers forms the intermixing between the bonding layers as they are transported to the trailing edge of the tool. In this situation, the rotating tool can cause a repeatable periodic structure within the depositing mass layers. The uniformity of these flow patterns depends on the consistency of the mechanical shearing bonds induced by the tool components (pin and shoulders) and the relevant homogeneity in material positioning. In this research, three flow distinct patterns were observed within the stirring zone at the cross-sections of the weld; S-line flow pattern (Figure 7a), swirling flow pattern (Figure 7b), and ellipse-shaped flow pattern (Figure 7c). All these three patterns were observed for the AA1100 samples, while the AA3003 weld samples only demonstrated the ellipse-shaped pattern at the highest applied speeds. For the AA1100 the maximum welding speeds led to the formation of the swirling flow pattern, elongated towards the sub-shoulder regions. This attributed to the effect of the shoulder rotation which is dominant in higher speeds, compared to the pin rotation in inducing of the mass flow. The shoulders have a wider contact surface with the workpiece material, and the intensified speeds can generate more frictional heat, and induce more stirring flow. This is a general interpretation, and the flow mechanism can be affected by the materials properties or the geometrical features on the tool surface (threads, flats, scrolls). 

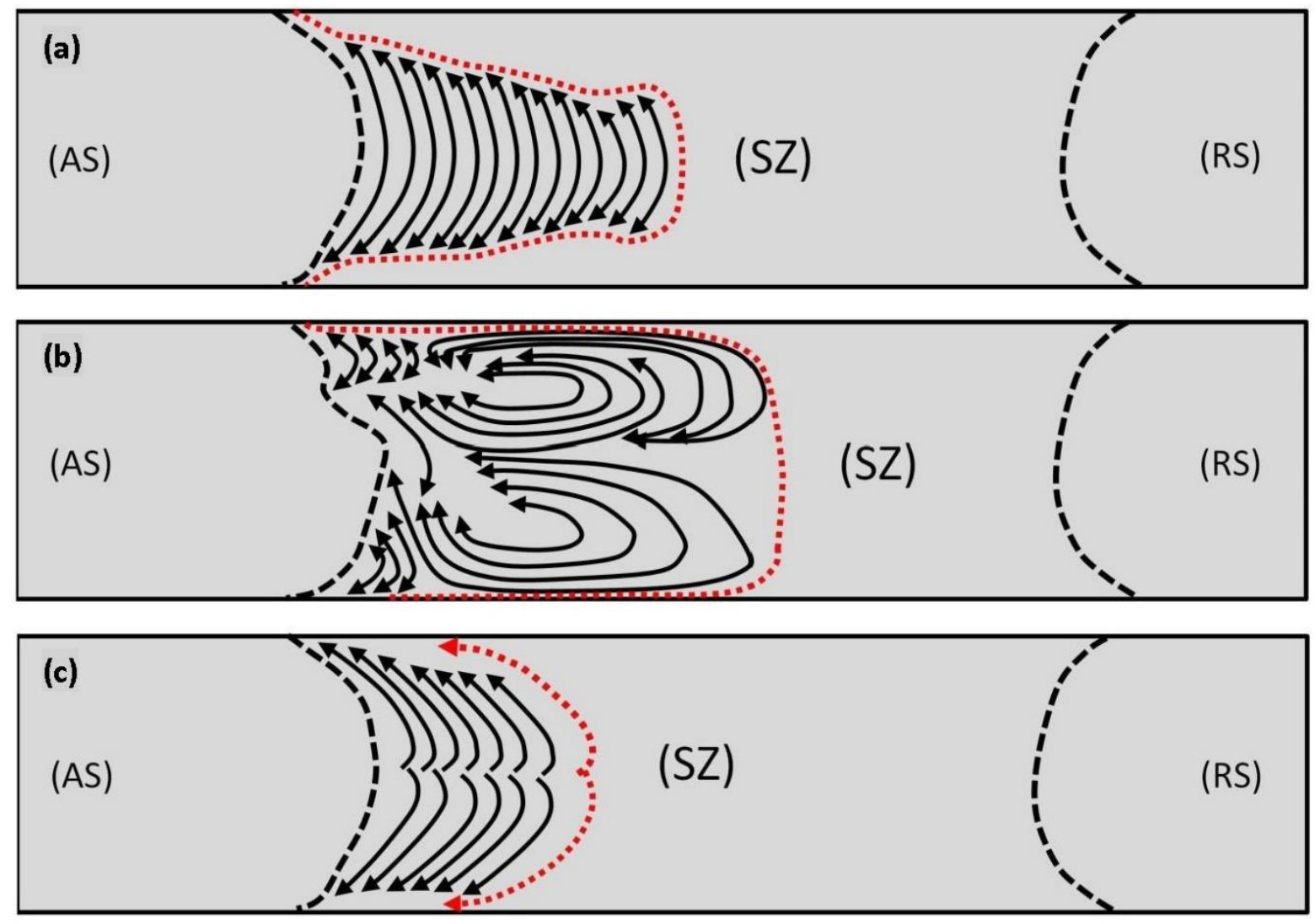

Fig. 7. Schematic of the flow patterns formed during the BFSW process within the SZ, observed for the AA1100 and AA3003 samples in this research; (a) S-line flow pattern, (b) Swirling-shape flow pattern,

(c) ellipse-shaped flow pattern

The effect of each welding parameter cannot be elucidated separately, as the macrostructure results cannot distinguish the combination of the welding parameters roles on the flow mechanism. However, the higher resolution of the flow patterns in higher speeds implies the importance of the welding speeds compared to the tool geometry and mechanical behaviour of the material. Splitting of the flow (flow segregation or partitioning) at higher speeds also shows the greater role of the shoulder performance, compared to the effect of the rotating pin. This is where defects occur at higher speeds, as the pin cannot adopt the mass transportation inconsistency with the flow induced by the shoulders. Therefore, interruption of the integrity between the deposited flow layers fails the refilling and emerging of the tunnel void discontinuity between the pin position and the AS border.

\section{Microstructure evolution}

Figure 8 shows the optical microscopy measurements for the microstructure of the mid-SZ for the AA1100 and AA3003 weld samples at $(600 \mathrm{rpm}, 400 \mathrm{~mm} / \mathrm{min})$ speeds set. The finegrained morphologies show the equiaxed recrystallization, under the tool performance and the induced severe plastic deformation. However, due to the magnification limitation of the optical microscopy, the grain boundary contrast is not pronounced enough for the uniform ultrafine grains of the mid-SZ. Hence, to overcome these limitations (magnification and resolution and contrast between the microscopic details of the grain structure), electron microscopy was utilized for the rest of the microstructure observations. 

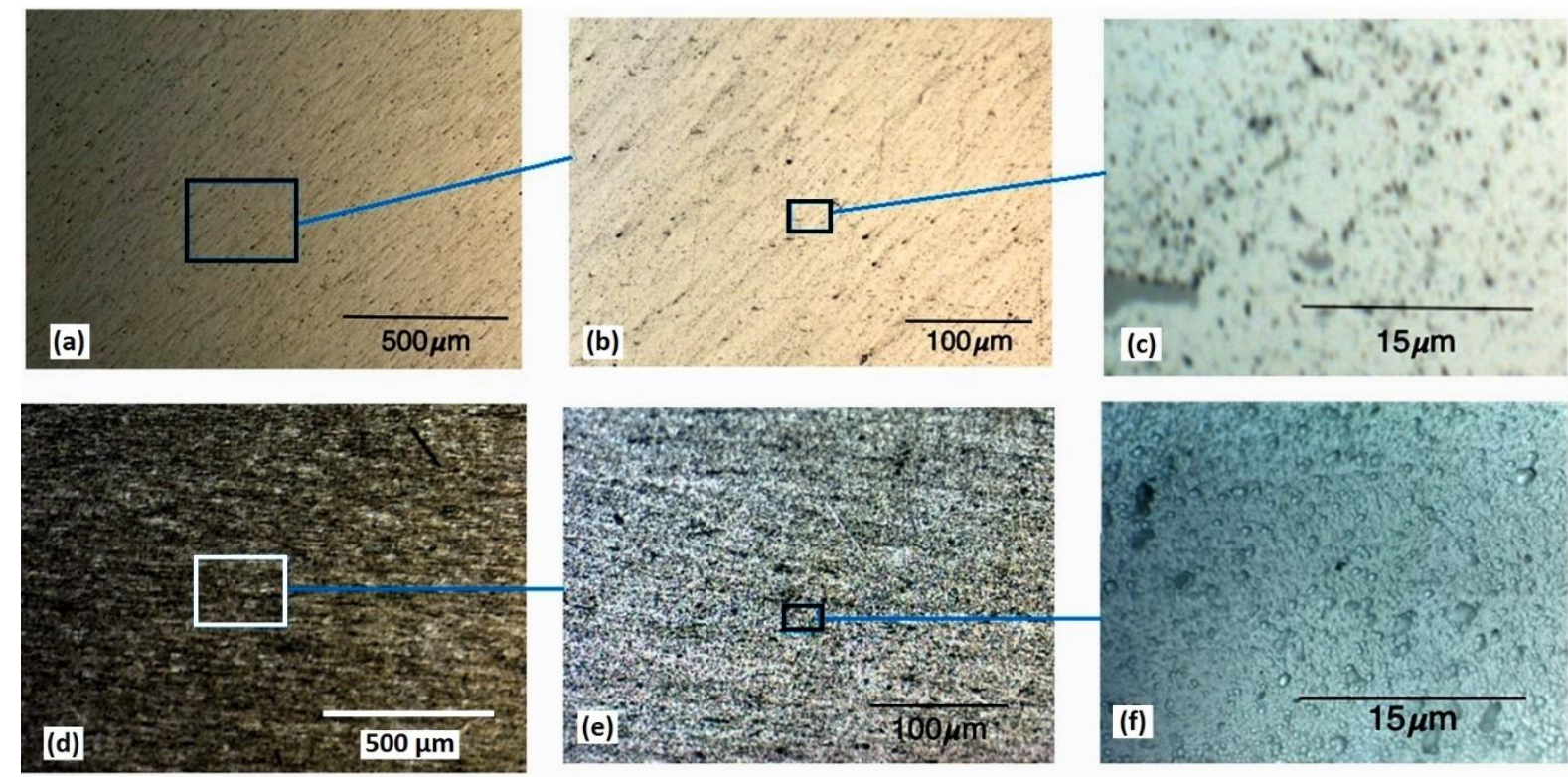

Fig. 8. Optical microscopy of the etched cross-section of the aluminium weld samples, at the mid-SZ; $(a, b, c)$ the AA1100 weld sample, and (d, e, f) the AA3003 weld sample, selected regions at different magnifications. Both aluminium weld samples were processed at the welding speeds set of (600 rpm,

$400 \mathrm{~mm} / \mathrm{min}$ )

Figures 9 and 10 show the SEM micrographs from selected frames of the mid-SZ, for the AA1100 and AA3003 weld samples, respectively. According to the material flow visualization, for each alloy, three sets of speed $-(400 \mathrm{rpm}, 200 \mathrm{~mm} / \mathrm{min}),(500 \mathrm{rpm}, 300 \mathrm{~mm} / \mathrm{min}),(600 \mathrm{rpm}$, $400 \mathrm{~mm} / \mathrm{min}$ )- were chosen for the SEM analysis. The comparison between the microstructures shows that the grain morphology has a similar trend in the coarseness of the morphological features with the increase of the welding speeds. Although the dynamic recrystallized structure was formed for all the samples, the differences in apparent coarseness of the grain size indicate more severe plastic deformation has been increased by elevating the welding speeds [27,37]. Figure 9c and Figure 10c demonstrate a morphological comparison of the AA1100 and AA3003 samples in the maximum speeds $(600 \mathrm{rpm}$ and $400 \mathrm{~mm} / \mathrm{min}$ ), respectively. The micrographs indicate that within the deformed structure, greater extent recrystallization occurs in AA3003 sample, compared to the AA1100. This can be attributed to the mechanical tool action, where the fully-featured bobbin tool applied for AA3003 (comprises a tri-flat threaded pin and scrolled shoulders) creates more uniform plastic deformation during the stirring process. The etched samples contain some pitting features which make it hard to inspect the grain boundaries for precipitation details within the microstructure. Therefore, SEM imaging needs to meet more advanced imaging modes to increase the resolution of the microscopic details. 


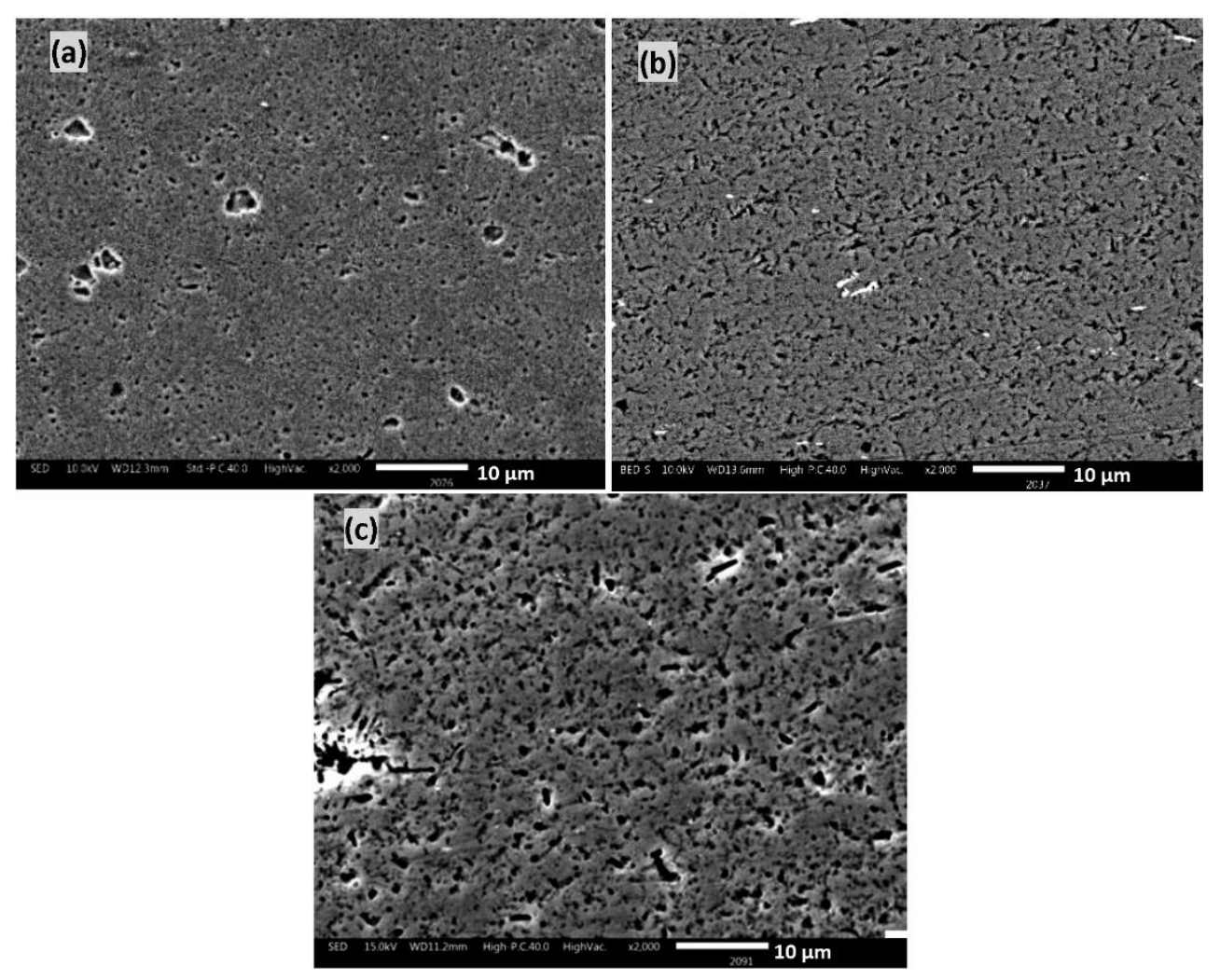

Fig. 9. SEM micrographs of the AA1100 weld samples, at the mid-SZ region, processed with different sets of speed; (a) $400 \mathrm{rpm}, 200 \mathrm{~mm} / \mathrm{min}$, (b) $500 \mathrm{rpm}, 300 \mathrm{~mm} / \mathrm{min}$, (c) $600 \mathrm{rpm}, 400 \mathrm{~mm} / \mathrm{min}$
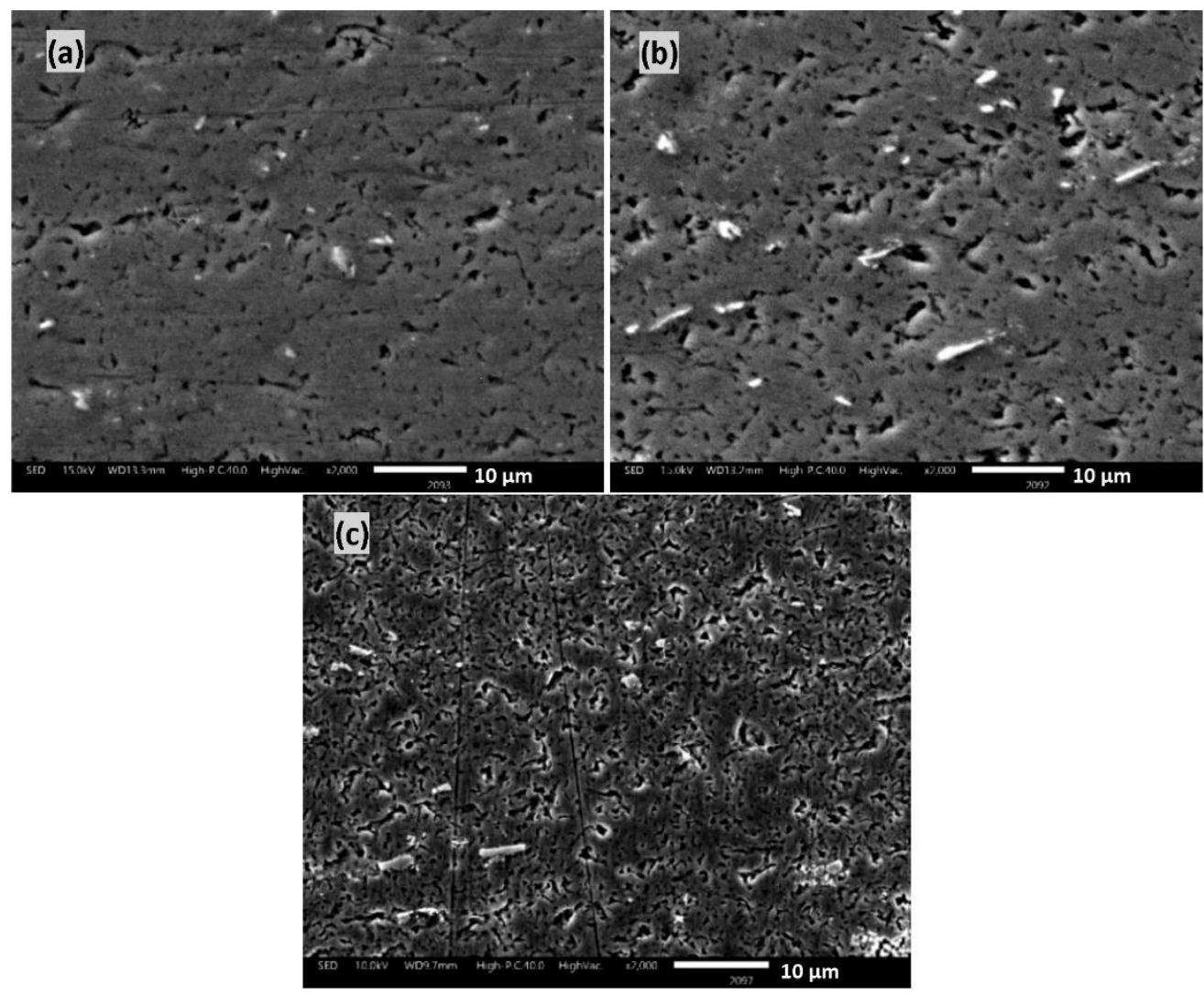

Fig. 10. SEM micrographs of the AA3003 weld samples, at the mid-SZ region, processed with different sets of speed; (a) $400 \mathrm{rpm}, 200 \mathrm{~mm} / \mathrm{min}$, (b) $500 \mathrm{rpm}, 300 \mathrm{~mm} / \mathrm{min}$, (c) $600 \mathrm{rpm}, 400 \mathrm{~mm} / \mathrm{min}$ 
SEM images produced by the secondary electrons (SE) process can provide better contrast in surface topography, therefore it enables showing of the grain boundaries ultrafine microstructures. The secondary electron imaging (SEI) applied in Figure 11, shows the morphology of the mid-SZ area for AA1100 and AA3003 weld samples processed in speeds set of $(600 \mathrm{rpm}, 400 \mathrm{~mm} / \mathrm{min})$. The grain boundary contrast is shown for both samples, where it shows the average grain size of the $5 \mu \mathrm{m}$ for the dynamic recrystallized structure of the stirred zone. The grain boundaries network for the AA3003 samples shows a better contrast compared to the grain, which can be related to the physical properties of the alloy or completion of the dynamic recrystallization (DRX) by the fully-featured tool, compared to the AA1100 sample with the featureless tool.
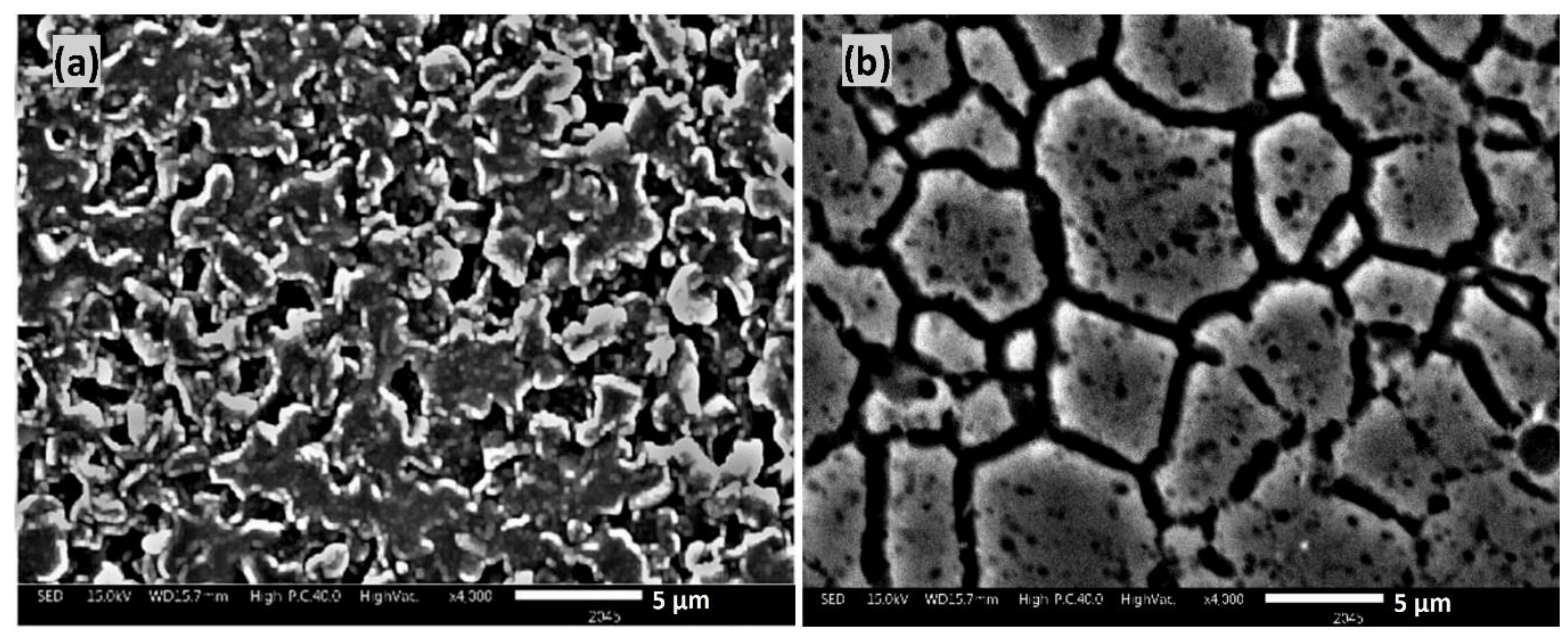

Fig. 11. The SEM micrographs (SE imaging mode) of the aluminium weld samples, at the mid-SZ; (a) the AA1100 weld sample, and (b) the AA3003 weld sample. Both aluminium weld samples were processed at the welding speeds set of $(600 \mathrm{rpm}, 400 \mathrm{~mm} / \mathrm{min})$

Precipitate particles with the ultrafine structure in a sub-micron scale need higher magnification to be properly observed through the micrographs. Backscattered electrons (BSE) have higher sensitivity in atomic numbers and can provide more details in phase contrast. Therefore, the BSE imaging can show the precipitates distinguishable from the Al-matrix.

Figure 12 shows the SEM micrographs in BSE imaging mode, with a better phase-contrast revealing the details of precipitation. The ultrafine precipitates are observed for both AA1100 and AA3003 at the mid-SZ, processed in speeds set of (600 rpm, $400 \mathrm{~mm} / \mathrm{min})$. The morphological observations demonstrate three different kinds of precipitates; ultrafine precipitates in sub-micron scale (zone 1), micro-size precipitates (zone 2), and the corroded particles (zone 3). The nature of the precipitates, chemical composition and formation mechanism is not clear in this stage. However, it can be concluded that the variety of size and morphology of the precipitates depends on different stages of the grain growth, occurring during the DRX mechanism. The corroded particles (region 3) have been partially removed within the surface area, affecting by the etching procedure. This is happening because of the selective dissolving of the silicon-compounds by the corrosive chemicals of the etchant reagents.

For a more quantitative analysis of the precipitation mechanism, the BSE results data have been processed to measure the details of the particle size and distribution as the secondary phase within the Al-phase matrix. 
Figure 13 shows the graphs of the BSE data processed by STATISTICA, elucidating the details of the precipitation; particles size and distribution, for the AA1100 and AA3003 samples, in mid-SZ (extracted from the micrographs in Figure 12).

The comparison between the information of the AA1100 and AA3003 samples shows that the average size of the precipitates in AA1100 sample $(6.5 \mu \mathrm{m})$, is more than those in the AA3003 sample $(1 \mu \mathrm{m})$. However, regarding the area occupied by the precipitates, the AA3003 has more precipitate content ( $7.5 \mathrm{vol} . \%)$ compared to the AA1100 (1.8 vol.\%). This can cause better precipitate hardening for the AA3003 sample, as the finer distributed particles (with the average size of $1 \mu \mathrm{m})$ allocate more volume portion of the structure $(7.5 \mathrm{vol} \%)$. This increases the surface-to-volume ratio of the secondary phase as the hardening particle and thus increasing their effectiveness as barriers to the movement of the dislocations [38]. Therefore, the finer precipitates can block more dislocations, create a pinning effect on the dislocation transitions, and subsequently act as a strengthening mechanism during the grain refinement caused by the DRX.
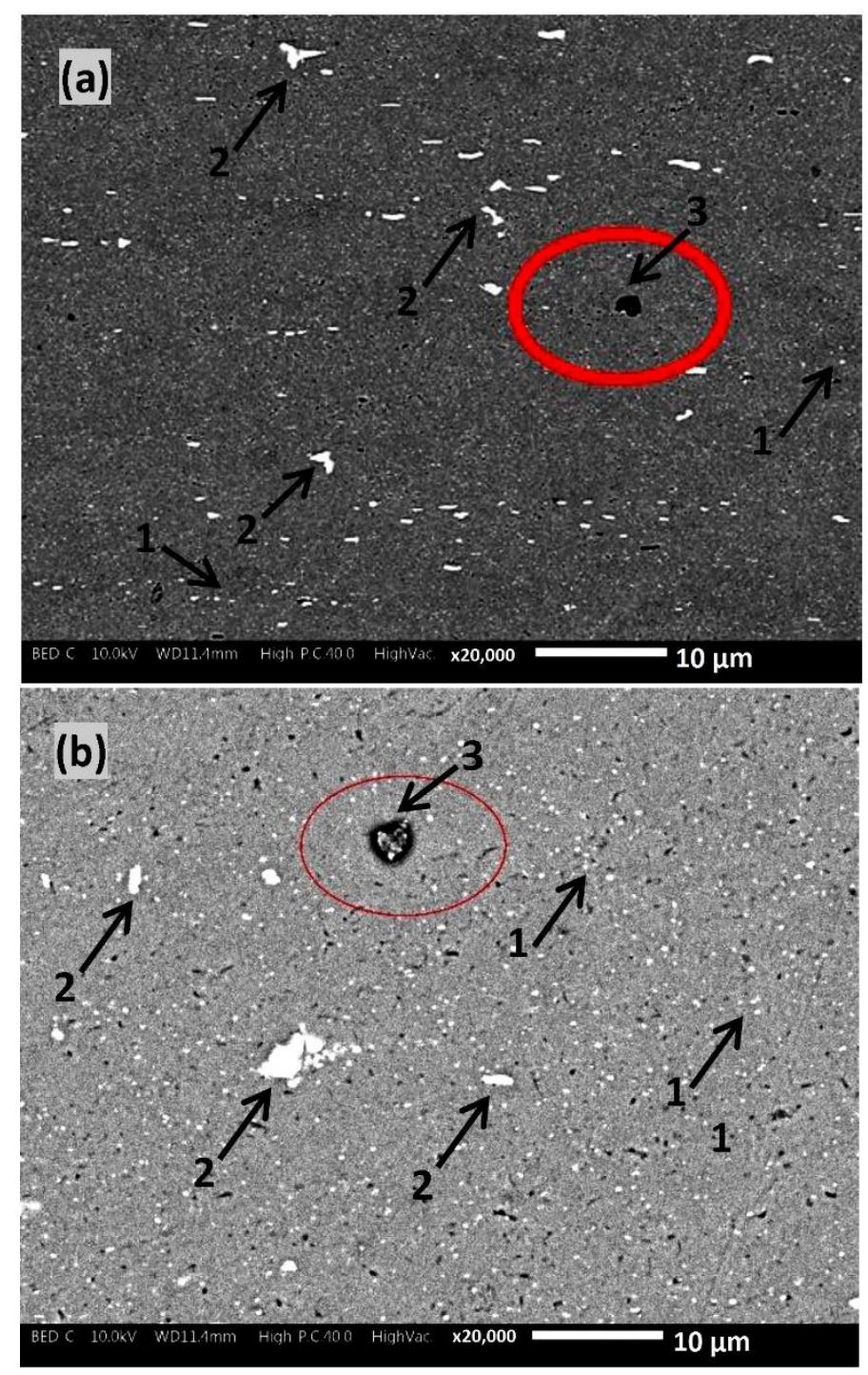

Fig. 12. The SEM micrographs (BSE imaging mode) of the aluminium weld samples, at the mid-SZ;

(a) the AA1100 weld sample, and (b) the AA3003 weld sample. Region 1; ultrafine precipitates, region 2; micro-size precipitates, region 3; corroded precipitates. Both aluminium weld samples were processed at the welding speeds set of (600 rpm, $400 \mathrm{~mm} / \mathrm{min}$ ) 

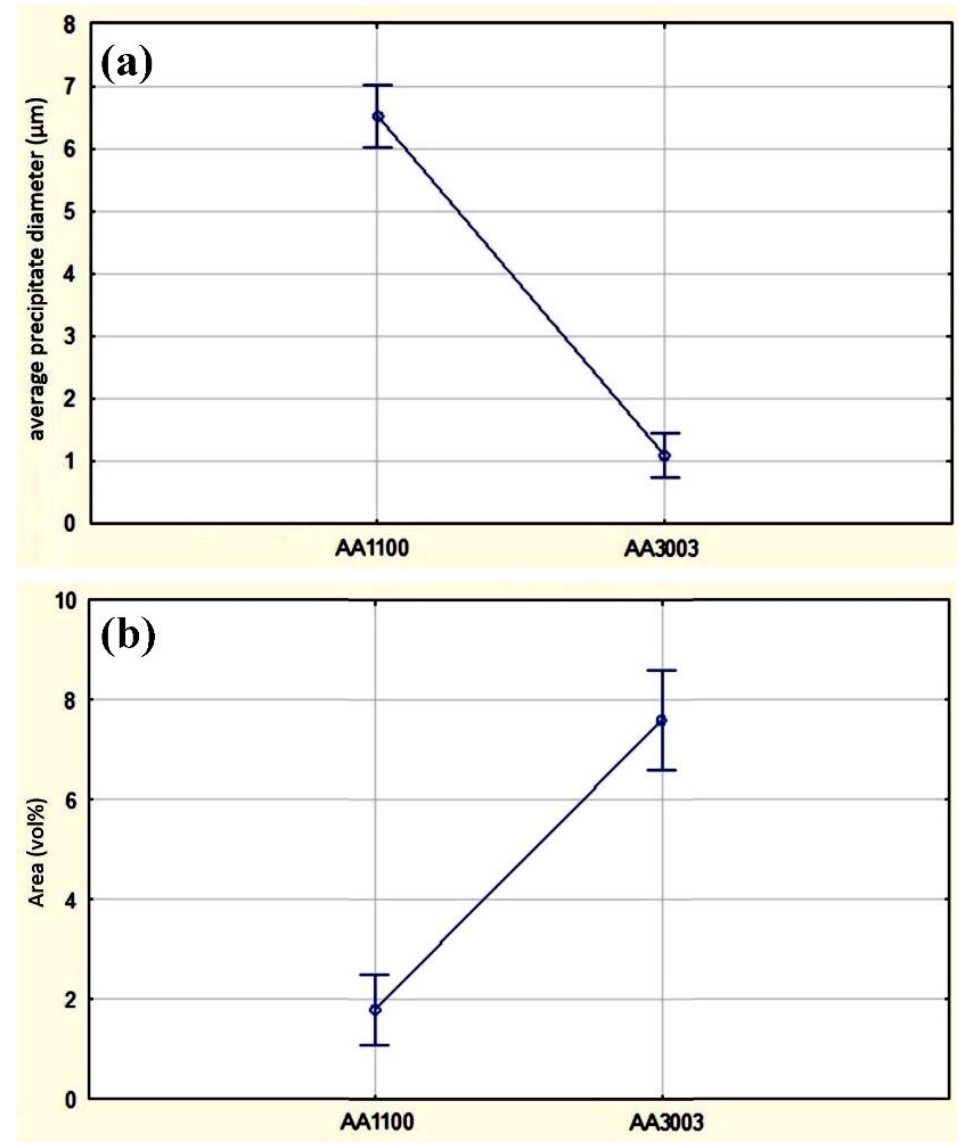

Fig. 13. Quantitative analysis of the backscattered electrons data, for the precipitation mechanism at the mid-SZ of the aluminium weld samples (AA1100 and AA3003); (a) the average diameter of precipitates in the specimens of AA1100 and AA3003, (b) the area of the precipitates (vol.\%) in the specimens of AA1100 and AA3003. Both aluminium weld samples were processed at the welding speeds set of $(600 \mathrm{rpm}, 400 \mathrm{~mm} / \mathrm{min})$

Grain refinement and DRX are the direct outcomes of the thermomechanical plastic deformation and the subsequent re-cooling after the stirring process. Alteration in grain boundary network, grain size and morphology and the subsequent precipitation cause a storedstrain, induced through the weld texture, which can cause a crystallographic misorientation within the polycrystalline structure. Electron Backscatter Diffraction (EBSD) analysis gives more crystallographic measurement details of the microstructure, elucidating the grain misorientation in graphical maps.

Figure 14 shows SEM micrographs and the relevant inverse pole figure (IPF) colouring orientation map of the microstructure of the mid-SZ for the AA1100 and AA3003 weld samples, both processed at speeds set of ( $500 \mathrm{rpm}, 300 \mathrm{~mm} / \mathrm{min})$.

The mid-SZ areas in both samples demonstrate an equiaxed recrystallized grain morphology in average grain size of below $5 \mu \mathrm{m}$, similar to the SE imaging results shown in Figure 11. The mechanical rotation of the tool within the stirring zone fragments the grain structure, followed by a severe plastic deformation intensified by the frictional heat input. The subsequent DRX forms ultrafine equiaxed grains randomly distributed in different crystallographic orientation. The nature of the grain misorientation is not fully understood yet, but it is attributed to the stored strain within the polycrystalline texture during the stirring, releasing during re-cooling and DRX. 

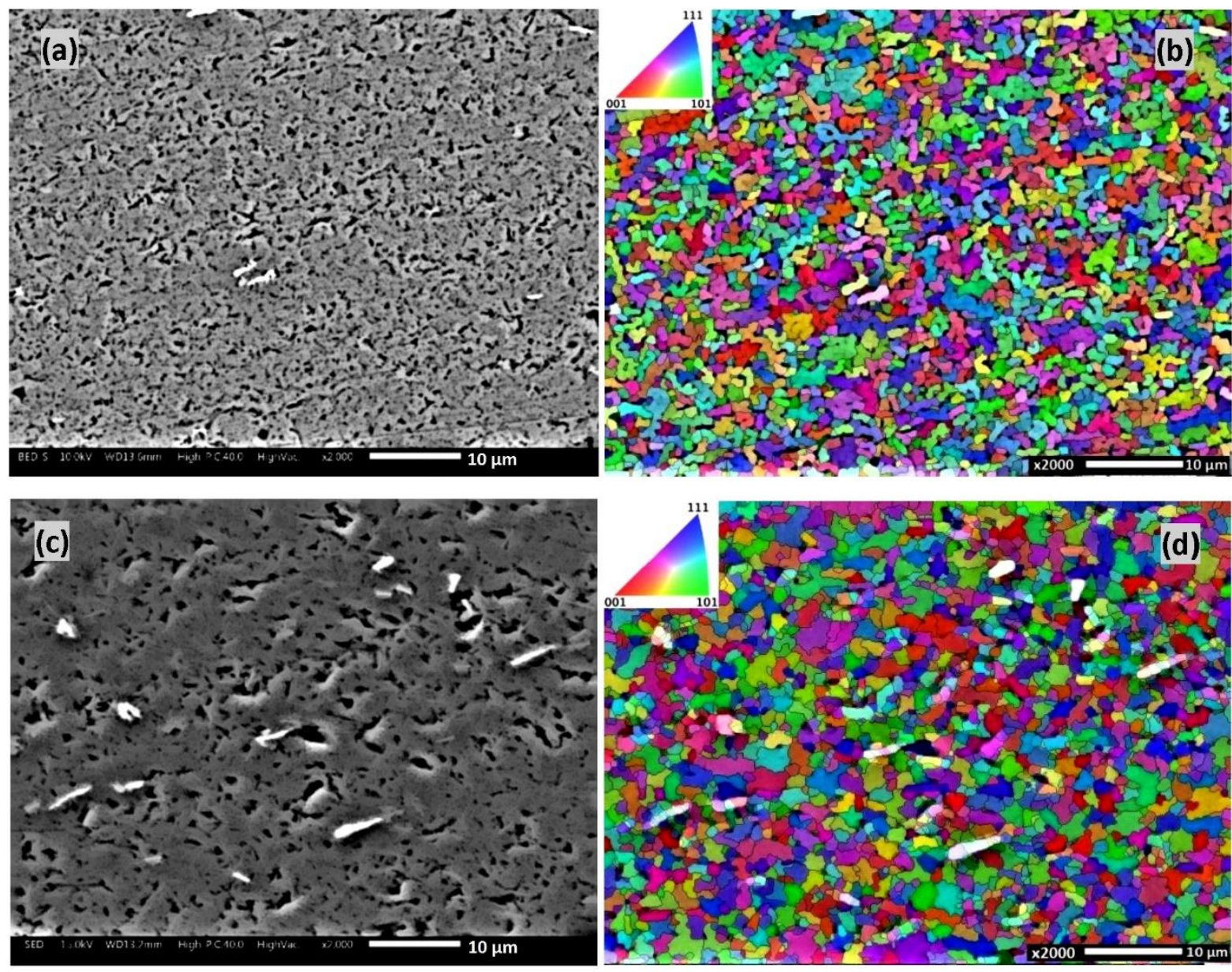

Fig. 14. The EBSD analysis of the aluminium weld samples, at the mid-SZ; $(a, b)$ the SEM micrograph, and the relevant IPF colour map for the AA1100 weld sample, respectively; (c, d) the SEM micrograph, and the relevant IPF colour map for the AA3003 weld sample, respectively. Both aluminium weld samples were processed at the welding speeds set of (500 rpm, $300 \mathrm{~mm} / \mathrm{min}$ )

In figure 15, the analysis of recrystallized fractions of the mid-SZ texture shows that the AA3003 sample possesses more progress in recrystallization (83\% fully-recrystallized and 14\% partially-recrystallized fraction), compared to the AA1100 sample (70\% fully-recrystallized and $18 \%$ partially-recrystallized fraction). This implies that under same welding speeds (600 $\mathrm{rpm}, 400 \mathrm{~mm} / \mathrm{min}$ ), the AA3003 sample (processed by the fully-featured tool) experienced more effective stirring action, compared to the AA1100 sample (processed by the single-piece simple tool).

The EBSD analysis can also denote the crystallographic misorientation information for the deformed and recrystallized grains texture. For the polycrystalline texture the main grainboundaries are recognised as the High-angle grain boundaries (HAGBs) threshold with a misorientation angle of $>15$ degrees [37]. Furthermore, the sub-grain scale alteration of the crystallographic orientation within the grains can be indicated by the sub-grain boundaries as the Low-angle grain boundaries (LAGBs) threshold. The stored strain induced by the thermomechanically stirring action can lead to accumulation of the dislocation within the grains restricted by the grain boundaries at the HAGBs. Subsequently, during the post-welding recooling procedure and DRX mechanism the internal stresses in the sub-grain scale reduce by a self-arrangement ordering of dislocations adopted in some preferential crystallographic planes. 
This leads to the formation of the LAGBs inside the grain, whereby resulting in a misorientation within the strain-relieved grains texture in sub-grain scale.

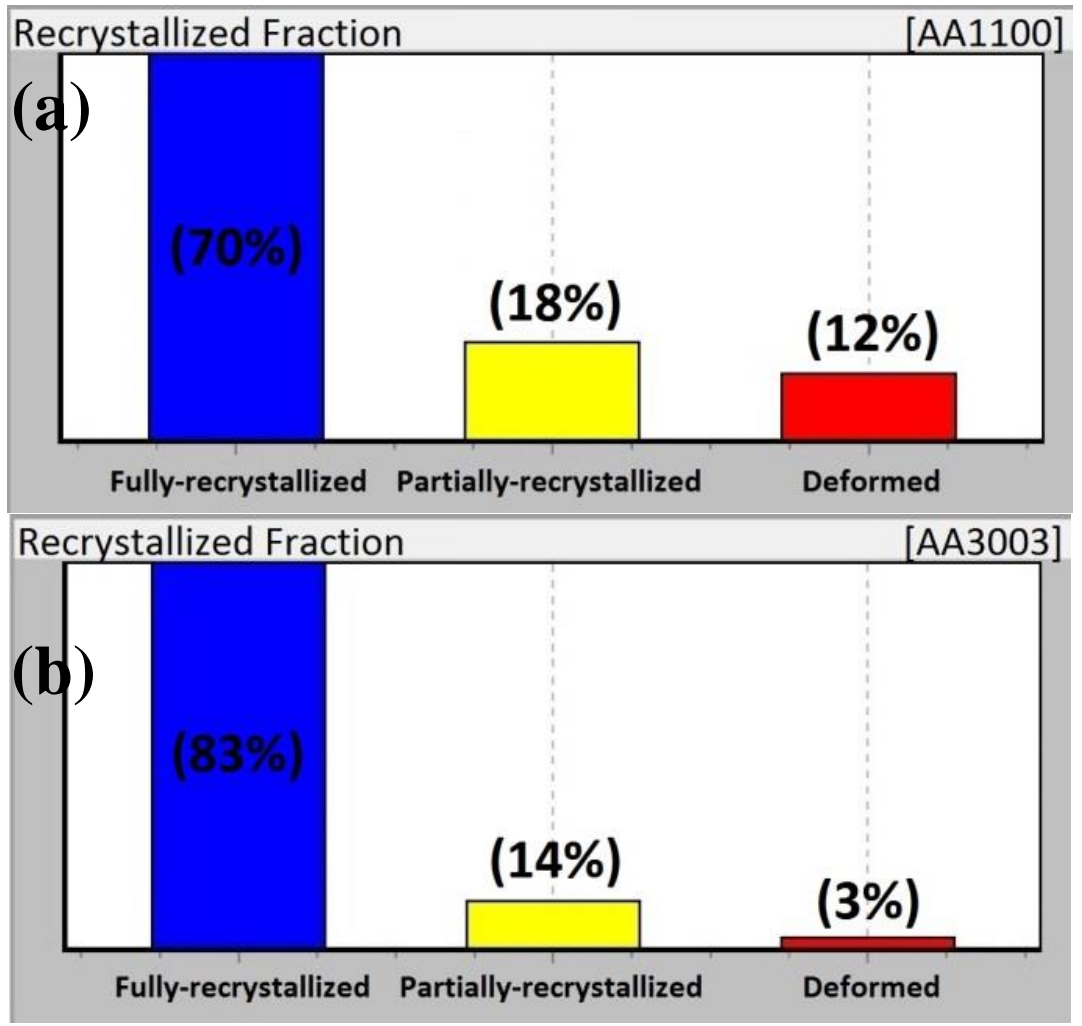

Fig. 15. Quantitative analysis of the recrystallized fraction for the aluminium weld samples, at the mid-

SZ; (a) the AA1100 weld sample, and (b) the AA3003 weld sample. Both aluminium weld samples were processed at the welding speeds set of $(600 \mathrm{rpm}, 400 \mathrm{~mm} / \mathrm{min})$

As demonstrated in Figure 16, the grain boundary networks are observed in the mid-SZ region for both AA1100 and AA3003 aluminium weld samples, both processed in similar welding speeds ( $600 \mathrm{rpm}, 400 \mathrm{~mm} / \mathrm{min}$ ). Figures $16 \mathrm{a}$,b correspond to the LAGBs network with the misorientation angle identified in $<2$ degrees, highlighted in red colour. Alternatively, the HAGBs network is highlighted in black colour, identified for the misorientation angle of $>15$ degrees, see Figures $16 \mathrm{c}$,d. The comparison between the misorientation maps in Figure 16 for the LAGBs and HAGBs distributions indicate a uniform DRX pattern occurred within the deformed texture of the mid-SZ, as a result of the plastic flow strain induced by the stirring pin. The comparison between Figures 16 a,b shows a higher density of the LAGBs (highlighted in red), at the mid-SZ of the AA1100 sample (Figure 16a), compared to the AA3003 sample (Figure 16b). This is attributed to a higher rate of the stored strain for the AA1100 sample compared to the AA3003, which is responsible for the formation of the LAGBs or sub-grain boundaries. However, the HAGBs angle orientation (in black colour) was shown to be approximately similar in both AA1100 and AA3003 samples, see Figures 16 c,d. Hence, it appears that the formation of the LAGBs is highly attributed to the strain localisation and the subsequent grain misorientation during the DRX mechanism. 

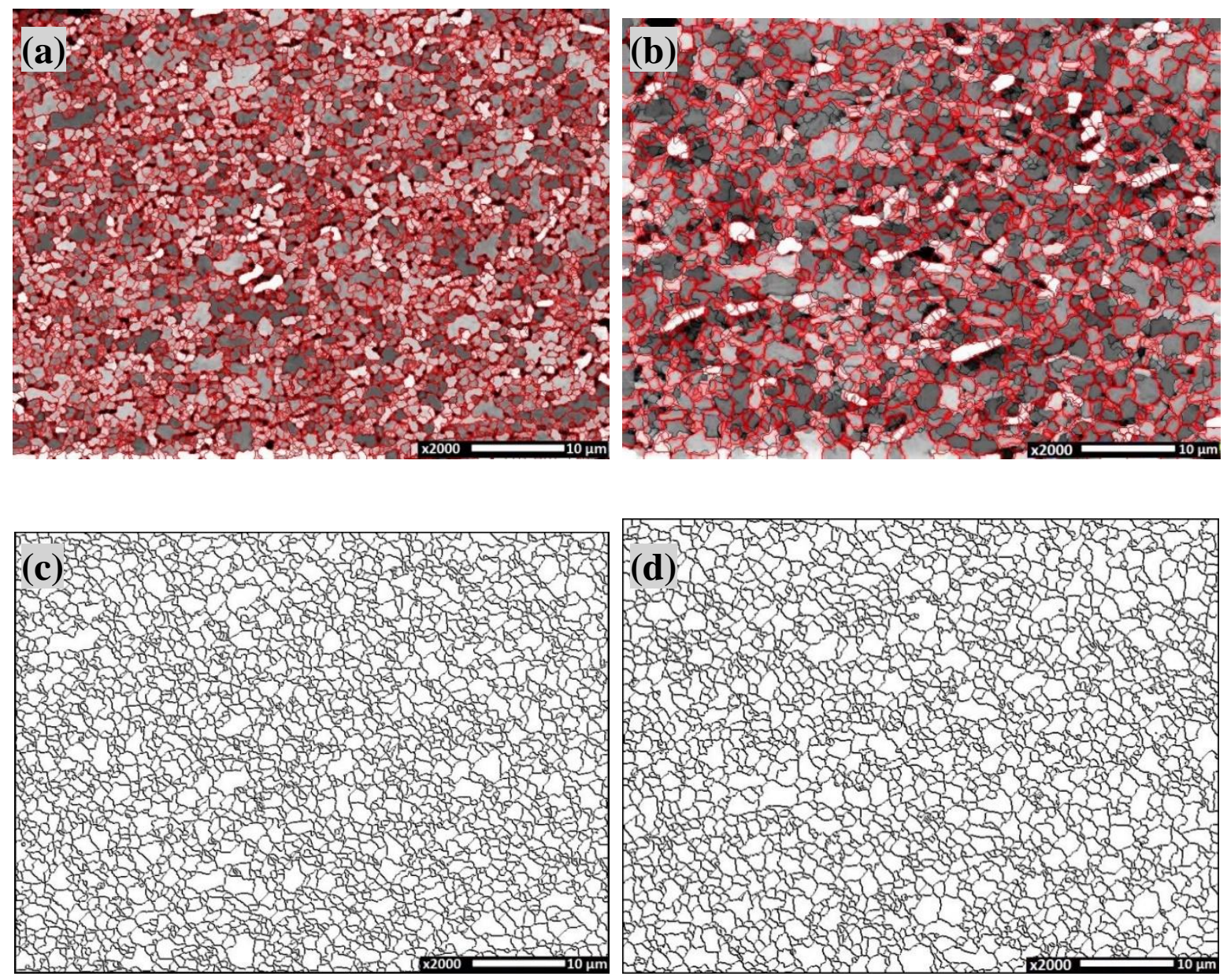

Fig. 16. EBSD orientation maps, corresponding to the misorientation angle distributions. $(a, b)$ band contrast map for the mid-SZ of the AA1100 and AA3003 BFSW weld plates, respectively (LAGBs highlighted in red colour, with the misorientation angle of <2 degrees); (c, d) HAGBs network, for the mid-SZ of the AA1100 and AA3003 BFSW weld plates, respectively (The misorientation angle of $>15$ degrees highlighted in black colour)

The material flow visualization measured within the cross-sections of the AA1100 and AA3003 BFSW weld plates revealed varieties of macro-features such as S-line shape, swirling like or ellipse-shaped flow patterns in the SZ. The increase in welding speeds (rotational and longitudinal) moves the flow towards the sub-shoulder regions, where the shoulder flow action seizes the majority of frictional heat generation, because of wider surface contact with the workpiece material, compared to the rotating pin. In this situation, the flow partitioning can interrupt the flow integrity where it eventually can emerge a discontinuity between the deposited mass layers to occur the tunnel void defect by the failure of the refilling mechanism, near the AS border of the SZ.

Microscopic analysis of the etched samples delineates some thermomechanical features at the mid-SZ region of the weld, where the severe plastic deformation and subsequent DRX form an ultrafine grain structure. The SEM micrographs showed a significant grain refinement compared to the parent metal, forming the equiaxed morphology with the grain size below 5 $\mu \mathrm{m}$ in mid-SZ. The DRX for the microstructures with different composition of the alloying elements can cause different precipitation through weld texture. During the DRX mechanism, the first step is the stirring action which deforms the grains by the severe fragmentation induced 
by the rotating tool. In the second step, the generated frictional heat can rearrange the dislocation arrays and form a new subdivision of the LAGBs and further transform them into HAGBs or new grain boundaries at the end of the DRX process. In both steps, the alloying elements of the aluminium grades can provide different conditions for the DRX. Therefore, the grain size of the final weld texture can be slightly different, as it is observed larger grains in AA3003 microstructure compared to AA1100.

Also, the EBSD maps confirmed a randomly distributed grain misorientation through the weld texture, which is because of the mechanical stirring action and the subsequent DRX. The DRX mechanism also forms a remarkable precipitation process within the microstructure which can improve the strength of the material by the precipitate hardening mechanism, different to the main body of the parent material. The precipitation effect in interaction with the dislocations in the crystalline lattice of the processed material leads to the observed grain refinement, where the LAGBs and HAGBs rearrange the grain boundary network. The EBSD analysis also indicated a high rate of the recrystallization within the SZ of the weld, where the fully-featured tool performed a more complete DRX within the texture, compared to the single-piece simple tool.

There is an interesting question regarding the precipitation kinetics of these alloys, AA1100 and AA3003. There are no known principles to scale all the features of the precipitation kinetics of the FSW-driven thermomechanical behaviour for these particular aluminium grades. In general, if it was possible to develop a kinetics approach to analyse the precipitation in the BFSW process, it would seem to require the development of a transport equation by considering the parameters and factors for the volume, mass, momentum, energy and others under specific geometry of the tool in a nonequilibrium plastic deformation for the forged/extruded material. Nevertheless, the real situation of the BFSW process is expected to be more complex because, the dynamic flow component imposes more difficulties to consider the respective coefficients for friction, mechanical strength, and material stiffness. Therefore, the precipitation kinetics is left for future work.

The EBSD results confirmed that for the Al alloys with the FCC structure [37] the precipitation occurred at two positions: the HAGBs between the main grains and also within the grain at the LAGBs. The increased density of the participate particles deposited at the LAGBs contributes to strain hardening as the blocking barriers of dislocation movement.

Our interpretation is that in severe deformation condition, the grain misorientation and the higher rates of the strain hardening can form the shear bands within the texture and consequently lead to the micro-crack emergence between the flow layers parallel to the deposition direction.

\section{SUMMARY}

This work describes the original contribution of identifying different flow patterns within the macro-etched cross-sections of the AA1100 and AA3003 BFSW weld plates. The material flow was created by the alteration of the operational parameters of the welding, e.g. feed rate, rotating speed and the tool geometry. The optical microscopy indicates that the interaction between the bobbin tool and the aluminium workpiece results in the formation of S-line, swirling like or ellipse-shaped flow patterns within the stirring zone of the weld structure. The overall interpretation is that the mutual interaction of the tool geometry and welding speeds influence the mass flow regimes to form different flow arm patterns during the deposition of the plasticized mass layers at the trailing edge of the tool, where the refilling process happens near the AS border of the weld. 
The comparison of the microscopic analysis between two aluminium grades (AA1100 and AA3003) confirms that the DRX progressed at the mid-SZ region of the weld. This is including the grain refinement, formation of the ultrafine equiaxed grain morphology, with a significant thermomechanical precipitation process during the stirring action and the subsequent re-cooling procedure. While the density of the sub-grain boundaries increased by the LAGBs threshold, the DRX showed a significant grain misorientation representative by the manipulated HAGBs with the mid-SZ texture. The EBSD analysis of the weld texture confirmed a randomly distributed grain misorientation induced by the mechanical performance of the bobbin-tool during the grain fragmentation of severe plastic deformation during the stirring action. The stored strain released during the DRX can stabilise the grain structure by the formation of a uniform grain structure with a significant modification of the grain size and polycrystalline morphology.

\section{ORCID iD:}

Abbas Tamadon (https://orcid.org/0000-0001-7367-4207)

Dirk J. Pons (https://orcid.org/0000-0001-7141-0291)

Kamil Sued (https://orcid.org/0000-0002-2990-7015)

Don Clucas (https://orcid.org/0000-0002-6724-3037)

\section{REFERENCES}

1. Thomas, W.; Nicholas, E.; Needham, J.; Murch, M.; Temple-Smith, P.; Dawes, C. Friction stir butt welding, international patent application no. PCT/GB92 Patent application 1991.

2. Thomas, W.; Wiesner, C.; Marks, D.; Staines, D. Conventional and bobbin friction stir welding of $12 \%$ chromium alloy steel using composite refractory tool materials. Science and Technology of Welding and Joining, 2009, 14, 247-253.

3. Threadgill, P.; Leonard, A.; Shercliff, H.; Withers, P. Friction stir welding of aluminium alloys. International Materials Reviews, 2009, 54, 49-93.

4. Threadgill, P.L.; Ahmed, M.; Martin, J.P.; Perrett, J.G.; Wynne, B.P. The use of bobbin tools for friction stir welding of aluminium alloys, Materials Science Forum, 6382010 1179-1184.

5. Colligan, K. Material flow behavior during friction welding of aluminum. Welding Journal, 1999, $75,229-237$.

6. Hilgert, J.; Dos Santos, J.; Huber, N. Shear layer modelling for bobbin tool friction stir welding. Science and Technology of Welding and Joining, 2012, 17, 454-459.

7. Hilgert, J.; Hütsch, L.L.; dos Santos, J.; Huber, N. Material flow around a bobbin tool for friction stir welding, Excerpt from the Proceedings of the COMSOL Conference, 2010.

8. Hilgert, J.; Schmidt, H.; Dos Santos, J.; Huber, N. Thermal models for bobbin tool friction stir welding. Journal of Materials Processing Technology, 2011, 211, 197-204.

9. Cui, L.; Yang, X.; Zhou, G.; Xu, X.; Shen, Z. Characteristics of defects and tensile behaviors on friction stir welded AA6061-T4 T-joints. Materials Science and Engineering: A, 2012, 543, 58-68. 
10. Durga, B.S. Research scholar optimization of friction stir welding parameters (tool material, tool geometry and tool speed) on aluminium alloys 6061 using Taguchi method. Advanced Research Journals of Science and Technology 2018, 5, 385-407.

11. Dialami, N.; Chiumenti, M.; Cervera, M.; Agelet de Saracibar, C.; Ponthot, J.P. Material flow visualization in friction stir welding via particle tracing. International Journal of Material Forming, 2015, 8, 167-181.

12. Dialami, N.; Cervera, M.; Chiumenti, M. Effect of the tool tilt angle on the heat generation and the material flow in friction stir welding. Metals, 2019, 9, 28.

13. He, X.; Gu, F.; Ball, A. A review of numerical analysis of friction stir welding. Progress in Materials Science 2014, 65, 1-66.

14. Hasan, A.F.; Bennett, C.J.; Shipway, P.H. A numerical comparison of the flow behaviour in friction stir welding (FSW) using unworn and worn tool geometries. Materials \& Design, 2015, 87, 10371046.

15. Egea, A.S.; Rodriguez, A.; Celentano, D.; Calleja, A.; de Lacalle, L.L. Joining metrics enhancement when combining FSW and ball-burnishing in a 2050 aluminium alloy. Surface and Coatings Technology, 2019, 367, 327-335.

16. Sued, M.; Pons, D.; Lavroff, J.; Wong, E.-H. Design features for bobbin friction stir welding tools: Development of a conceptual model linking the underlying physics to the production process. Materials \& Design, 2014, 54, 632-643.

17. Thomas, W.; Nicholas, E. Friction stir welding for the transportation industries. Materials \& Design, 1997, 18, 269-273.

18. Wang, G.-Q.; Zhao, Y.-H.; Tang, Y.-Y. Research progress of bobbin tool friction stir welding of aluminum alloys: A review. Acta Metallurgica Sinica (English Letters), 2020, 33(1), 1-17.

19. Fuse, K.; Badheka, V. Bobbin tool friction stir welding: A review. Science and Technology of Welding and Joining, 2019, 24, 277-304.

20. Gadakh, V.S.; Adepu, K. Heat generation model for taper cylindrical pin profile in FSW. Journal of Materials Research and Technology, 2013, 2, 370-375.

21. Tamadon, A.; Pons, D.; Sued, K.; Clucas, D. Development of metallographic etchants for the microstructure evolution of A6082-T6 BFSW welds. Metals, 2017, 7, 423.

22. Tamadon, A.; Pons, D.J.; Clucas, D.; Sued, K. Internal material flow layers in AA6082-T6 buttjoints during bobbin friction stir welding. Metals, 2019, 9, 1059.

23. Sued, M.K. Fixed bobbin friction stir welding of marine grade aluminium. Ph.D. Thesis, University of Canterbury, Christchurch, New Zealand, 2015.

24. Tamadon, A.; Pons, D.J.; Clucas, D.; Sued, K. Texture evolution in AA6082-T6 BFSW welds: Optical microscopy and EBSD characterisation. Materials, 2019, 12, 3215.

25. Tamadon, A.; Pons, D.; Sued, K.; Clucas, D. Thermomechanical grain refinement in AA6082-T6 thin plates under bobbin friction stir welding. Metals, 2018, 8, 375.

26. Chen, S.; Lu, A.; Yang, D.; Lu, S.; Dong, J.; Dong, C. In: Analysis on flow pattern of bobbin tool friction stir welding for 6082 aluminum, Proceedings of the 1st International joint symposium on joining and welding, 2013; Elsevier: 353-358.

27. Tamadon, A.; Baghestani, A.; Bajgholi, M.E. Influence of WC-based pin tool profile on microstructure and mechanical properties of AA1100 FSW welds. Technologies, 2020, 8, 34.

28. Kerrar, G.; Merah, N.; Shuaib, A.N.; Fadi, A.-B.; Bazoune, A. Experimental and numerical investigations of friction stir welding of aluminum to copper. In: Applied mechanics, behavior of materials, and engineering systems, Springer: 2017; 129-138. 
29. Tamadon, A.; Pons, D.; Sued, K.; Clucas, D. Formation mechanisms for entry and exit defects in bobbin friction stir welding. Metals, 2018, 8, 33.

30. Tamadon, A. Characterization of flow-based bobbin friction stir welding process. Ph.D. Thesis, University of Canterbury, Christchurch, New Zealand, 2019.

31. Tamadon, A.; Pons, D.; Clucas, D. Analogue modelling of flow patterns in bobbin friction stir welding by the dark-field/bright-field illumination method. Advances in Materials Science, 2020, 20, 56-70.

32. Tamadon, A.; Pons, D.J.; Clucas, D. Structural anatomy of tunnel void defect in bobbin friction stir welding, elucidated by the analogue modelling. Applied System Innovation, 2020, 3, 2.

33. Tamadon, A.; Pons, D.J.; Clucas, D. Flow-based anatomy of bobbin friction-stirred weld; AA6082T6 aluminium plate and analogue plasticine model. Applied Mechanics, 2020, 1, 3-19.

34. Krishnan, K. On the formation of onion rings in friction stir welds. Materials Science and Engineering: A, 2002, 327, 246-251.

35. Teimournezhad, J.; Masoumi, A. Experimental investigation of onion ring structure formation in friction stir butt welds of copper plates produced by non-threaded tool pin. Science and Technology of Welding and Joining, 2010, 15, 166-170.

36. Tamadon, A.; Pons, D.; Chakradhar, K.; Kamboj, J.; Clucas, D.; Clucas, D. 3D-printed tool shoulder design for the analogue modelling of bobbin friction stir weld joint quality. Advances in Materials Science, 2021, 21, 27-42.

37. Tamadon, A.; Pons, D.; Clucas, D. EBSD characterization of bobbin friction stir welding of AA6082-T6 aluminium alloy. Advances in Materials Science, 2020, 20, $49-74$.

38. Tamadon, A.; Pons, D.J.; Clucas, D. AFM characterization of stir-induced micro-flow features within the AA6082-T6 BFSW welds. Technologies, 2019, 7, 80. 